\title{
The fungal metabolite chaetocin is a sensitizer for pro-apoptotic therapies in glioblastoma
}

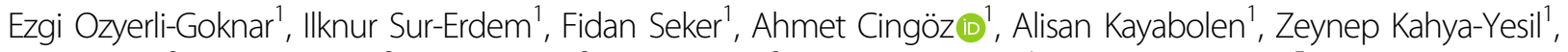 \\ Firat Uyulur ${ }^{2}$, Melike Gezen ${ }^{3}$, Nazife Tolay ${ }^{3}$, Batu Erman³, Mehmet Gönen ${ }^{4}$, James Dunford (10), \\ Udo Oppermann (10,6,7 and Tugba Bagci-Onder (1)
}

\begin{abstract}
Glioblastoma Multiforme (GBM) is the most common and aggressive primary brain tumor. Despite recent developments in surgery, chemo- and radio-therapy, a currently poor prognosis of GBM patients highlights an urgent need for novel treatment strategies. TRAIL (TNF Related Apoptosis Inducing Ligand) is a potent anti-cancer agent that can induce apoptosis selectively in cancer cells. GBM cells frequently develop resistance to TRAIL which renders clinical application of TRAIL therapeutics inefficient. In this study, we undertook a chemical screening approach using a library of epigenetic modifier drugs to identify compounds that could augment TRAIL response. We identified the fungal metabolite chaetocin, an inhibitor of histone methyl transferase SUV39H1, as a novel TRAIL sensitizer. Combining low subtoxic doses of chaetocin and TRAIL resulted in very potent and rapid apoptosis of GBM cells. Chaetocin also effectively sensitized GBM cells to further pro-apoptotic agents, such as FasL and BH3 mimetics. Chaetocin mediated apoptosis sensitization was achieved through ROS generation and consequent DNA damage induction that involved P53 activity. Chaetocin induced transcriptomic changes showed induction of antioxidant defense mechanisms and DNA damage response pathways. Heme Oxygenase 1 (HMOX1) was among the top upregulated genes, whose induction was ROS-dependent and HMOX1 depletion enhanced chaetocin mediated TRAIL sensitization. Finally, chaetocin and TRAIL combination treatment revealed efficacy in vivo. Taken together, our results provide a novel role for chaetocin as an apoptosis priming agent and its combination with pro-apoptotic therapies might offer new therapeutic approaches for GBMs.
\end{abstract}

\section{Introduction}

Glioblastoma multiforme (GBM) is grade IV glioma ${ }^{1}$ that represents $>45 \%$ of primary brain tumors with an incidence of 3.2/100,000 per year ${ }^{2}$. As standard of care, surgery with maximal tumor resection followed by external-beam radiation with concomitant Temozolomide therapy is applied. Despite recent therapeutic developments $^{3}$, the median survival for GBM patients is 14.6 months, and only a small fraction of patients (3\%) live

Correspondence: Tugba Bagci-Onder (tuonder@ku.edu.tr)

${ }^{1}$ Brain Cancer Research and Therapy Laboratory, Koç University School of Medicine, 34450 Istanbul, Turkey

${ }^{2}$ Department of Computational Biology, Koç University, 34450 Istanbul, Turkey Full list of author information is available at the end of the article

Edited by G. Melino longer than 5 years after diagnosis ${ }^{4,5}$ highlighting an unmet need to develop alternative treatment strategies.

One therapeutic strategy is to selectively induce cancer cell death. Apoptosis is a programmed cellular selfdestruction process ${ }^{6}$, which fosters the maintenance of tissue homeostasis through elimination of pre-malignant cells, therefore it is a barrier for cancer progression. Apoptosis can be triggered extrinsically with proapoptotic ligands, such as tumor necrosis factor-related apoptosisinducing ligand (TRAIL) ${ }^{7}$ that utilize the death receptors (DR4/DR5), Death Inducing Signaling Complex (DISC) and initiator caspases (caspases 8 and 10$)^{8}$. Intrinsic apoptosis is activated via DNA damaging drugs ${ }^{9}$ or other agents, such as $\mathrm{BH} 3$ mimetics $^{10}$, which involves mitochondrial outer membrane permeabilization via BAK or

\section{(c) The Author(s) 2019}

(c) (i) Open Access This article is licensed under a Creative Commons Attribution 4.0 International License, which permits use, sharing, adaptation, distribution and reproduction cc) in any medium or format, as long as you give appropriate credit to the original author(s) and the source, provide a link to the Creative Commons license, and indicate if changes were made. The images or other third party material in this article are included in the article's Creative Commons license, unless indicated otherwise in a credit line to the material. If material is not included in the article's Creative Commons license and your intended use is not permitted by statutory regulation or exceeds the permitted use, you will need to obtain permission directly from the copyright holder. To view a copy of this license, visit http://creativecommons.org/licenses/by/4.0/. 
BAX, consequent Cytochrome $\mathrm{C}$ release and effector caspase activation ${ }^{11,12}$. The link between extrinsic and intrinsic apoptosis is established by BID, which is truncated by active Casp8 and lead to oligomerization of BAK or BAX into mitochondrial pores.

Apoptosis induction by TRAIL is selective for cancer cells ${ }^{13,14}$. However, most cancer cell types, such as chronic lymphocytic leukemia ${ }^{4}$, medulloblastoma ${ }^{15}$, astrocytoma $^{16}$, and glioma ${ }^{17}$ are resistant to TRAIL, which render clinical application of TRAIL inefficient. Resistance might stem from changes in the balance of proapototic and anti-apoptotic signal mediators, mutations, altered glycosylation, dysregulated endocytosis, reduced expression of death receptors, and overexpression of decoy receptors ${ }^{18}$.

Epigenetic modulation of death receptor mediated pathway has been a successful approach for increasing TRAIL efficacy on tumor cells. To this end, histone deacetylase (HDAC) inhibitors, such as MS275 ${ }^{19}$, SAHA $^{20}$, Valproic acid ${ }^{21}$, Depsipeptide ${ }^{22}, \mathrm{SBHA}^{23}$, LAQ824 ${ }^{24}$ have been shown to augment TRAIL responses in various tumor types including prostate cancer, primary myeloid leukemia, melanoma, breast cancer, medulloblastoma, CLL, and GBM. Alteration of DNA methylation has also been proven to be effective in modulating TRAIL response of hepatoma, Burkitt's lymphoma, SCLC cells as exemplified by 5 -aza-2'-deoxycytidine treatment $^{15,25}$, combination treatment of decitabine and Valproic acid ${ }^{26}$, treatment with DNMT1 inhibitor Iso- $3^{27}$ and by DNMT1 and DNMT3b silencing ${ }^{28}$.

Epigenetic compounds that could change the expression of apoptosis-related machinery could be excellent secondary agents to augment TRAIL efficacy. However, to our knowledge, there has been no epigenetic drugcentered chemical screen conducted for GBM cells. Here, we undertook a chemical screening approach to identify novel TRAIL-sensitizers from a library of different epigenetic modifier chemical probes. Testing the efficacy of each individual drug alone and on potentiation of TRAIL response in GBM cells, the screen revealed the fungal metabolite chaetocin, previously identified as unselective histone methyltransferase inhibitor $^{29}$ as a potential TRAIL-sensitizing agent. The apoptosis potentiating effects of chaetocin involved induction of ROS and modulation of stress response and DNA damage pathways in GBM cells.

\section{Materials and methods Cell culture}

U87MG, U373, and T98G GBM cell lines were purchased from American Tissue Type Culture Collection (ATCC) and authenticated. U87MG-TR cells were TRAIL resistant derivatives of U87MG cells (manuscript under review). 293T cells were kind gift of Dr. Tamer Onder
(Koç University, Turkey). Cells were grown in DMEM medium (Gibco, USA) supplemented with \%10 fetal bovine serum (Gibco, USA) and \%1 Pen/Strep (Gibco, USA) in humidified incubator at $37{ }^{\circ} \mathrm{C}$ with $5 \% \mathrm{CO}_{2}$ level. Primary cell line GBM8 was obtained from Dr. Hiroaki Wakimoto (Massachusetts General Hospital, Boston, MA) and grown as neurospheres in cell culture flasks containing EF medium (Neurobasal medium supplemented with EGF, FGF, B-27, N2, Heparin, L-Glutamine, and Pen/Strep).

\section{Reagents}

TRAIL was commercially supplied (SuperKiller, Enzo Life Sciences, Farmingdale, NY, USA) or produced from 293T cells as described ${ }^{30}$. Caspase inhibitors (BD Pharmingen, San Diego, CA, USA) were: Z-VAD-FMK (general caspase inhibitor), Z-FA-FMK (negative control). Bcl2, Bcl-xL inhibitors ABT-263 and WEHI-539 were purchased from Cayman Chemicals (Ann Arbor, MI, USA). FasL and N-acetyl-L-cysteine (NAC) were purchased from Sigma-Aldrich (MO, USA). NUTLIN-3a was purchased from MedChemExpress (NJ, USA). Doxycycline was purchased from Sigma-Aldrich (Cat. No: D9891). Dluciferin was purchased from Biotium (CA, USA). Chaetocin was purchased from two sources (C9492-1mg, Sigma-Aldrich, MO, USA) and (S8068, Selleckchem, Houston, TX, USA). The epigenetic tool library was constructed as described ${ }^{31}$.

\section{Cell viability, caspase activity, and caspase inhibition assays}

Cell viability was detected by ATP based Cell Titer-Glo (CTG) Luminescent Cell Viability Assay (Promega) according to the manufacturer's instructions using a plate reader (BioTek's Synergy H1, Winooski, VT, USA). 5000 cells/well were seeded to 96-well plates (Corning Costar, clear bottom black side) as triplicates for each condition and treated with corresponding chemicals of interest for defined period. For all cell viability assays, Chaetocin was applied simultaneously with apoptosis inducers (TRAIL/ FasL/BH3 mimetics). For caspase inhibition assay, cells were subjected to Chaetocin treatment for $24 \mathrm{~h}$ prior to TRAIL treatment. Z-FA-FMK (Negative Control for Caspase Inhibitors) or Z-VAD-FMK (General Caspase Inhibitor) pretreatments were performed at $20 \mu \mathrm{M}$ final concentration for $24 \mathrm{~h}$ before the following drug treatments. For caspase activity assays, cells were treated with chaetocin $(100 \mathrm{~nm}, 24 \mathrm{~h})$ followed by TRAIL $(100 \mathrm{ng} / \mathrm{ml}$ for $3 \mathrm{~h}$ ). Caspase $3 / 7$ activity was measured by CaspaseGlo ${ }^{\circledR}$ 3/7 (Promega) assays according to manufacturer's instructions. For measurement of caspase activity, cells were subjected to Chaetocin treatment for $24 \mathrm{~h}$ followed by TRAIL treatment for $3 \mathrm{~h}$ since caspase cleavage is evident at early stages of apoptosis. NAC was used as ROS 
scavenger. Cells were pretreated with NAC $(10 \mu \mathrm{M})$ for $24 \mathrm{~h}$. Next day cells were treated with the drug of interest in the presence of NAC and cell viability was measured.

\section{Live cell imaging}

All live-cell imaging experiments were carried out by Olympus Xcellence Pro inverted microscope (Center Valley, PA, USA) with a $\times 10$ air objective in a chamber at $37^{\circ} \mathrm{C}$, supplied with $5 \% \mathrm{CO}_{2}$. Cells were seeded as 150.000 cells/well to 6-well plates and treated with chemicals of interest simultaneously in combination. Time-lapse images were captured right after drug treatments with 5 or $6 \mathrm{~min}$ intervals. From each well, random positions were recorded to obtain image stacks and death/live cells in each image were counted using the ImageJ Software (NIH Image, Bethesda, MD, USA). Quantifications were performed by counting 3 different image fields for each condition for selected time points.

\section{Quantitative RT-PCR}

RNA isolation and cDNA synthesis were performed as described $^{32}$. Primers used for qPCR are listed in Supplementary Table 1.

\section{Western blotting}

Western blots were performed as described ${ }^{32}$. Cells were treated with Chaetocin for $24 \mathrm{~h}$ followed by $3 \mathrm{~h}$ TRAIL treatment to check caspase cleavage, Bid truncation and PARP cleavage. Western blots involving NACtreated samples were performed on cells pretreated with NAC for $24 \mathrm{~h}$ followed by Chaetocin and TRAIL simultaneous combinatorial treatment for additional $24 \mathrm{~h}$. All antibodies are listed in Supplementary Table 2.

\section{Annexin V/PI staining}

Cells were seeded to 6-well plates (300,000 cells/well). After simultaneous treatment with chaetocin and TRAIL (100 $\mathrm{nM}$ and $100 \mathrm{ng} / \mathrm{ml}$, respectively, for $24 \mathrm{~h}$ ), all cells (both live cells attached to culture plate and dead cells free floating in medium) were harvested and pelleted. Pellets were washed in cold PBS, centrifuged and resuspended in $500 \mu \mathrm{l} 1 \times$ Annexin binding buffer $(1 \times$ $10^{6} \mathrm{cell} / \mathrm{ml}$ ). One hundred microliter of cell suspension was transferred to BD flow tubes and $5 \mu \mathrm{l}$ of Alexa Fluor 488 Annexin V (ThermoFisher, Waltham, MA, USA) and $1 \mu \mathrm{l}$ of $100 \mu \mathrm{g} / \mathrm{ml}$ PI working solution $(5 \mu \mathrm{l}$ of $1 \mathrm{mg} /$ $\mathrm{ml}$ PI stock diluted in $45 \mu \mathrm{l}$ Annexin binding buffer) were added. Cell suspension was incubated at room temperature for $15 \mathrm{~min}$. Four hundred microliter Annexin V binding buffer was added. Stained cells were analyzed by BD Accuri C6 (BD Biosciences, USA) flow cytometer (excitation $488 \mathrm{~nm}$, emission 530/575 nm) and 10,000 events were recorded for each sample.

\section{Terminal deoxynucleotidyl transferase dUTP nick end labeling (TUNEL) assay}

Cells were seeded to 12 -well plates $(25,000$ cells/well $)$ on glass coverslips. Chaetocin and TRAIL simultaneous treatment (100 nM, $100 \mathrm{ng} / \mathrm{ml}$, respectively) was performed for $24 \mathrm{~h}$. After washing with PBS, air dried cells were fixed by $300 \mu$ l fixation solution (4\% PFA in PBS, $\mathrm{pH} 7.4$, freshly prepared) at $4{ }^{\circ} \mathrm{C}$ for $1 \mathrm{~h}$. After rinsing 3 times with PBS, $300 \mu \mathrm{l}$ Blocking solution $\left(3 \% \mathrm{H}_{2} \mathrm{O}_{2}\right.$ in methanol) was added for $10 \mathrm{~min}$ at RT. Coverslips were rinsed with PBS 3 times and then incubated in $30 \mu \mathrm{l}$ permeabilization solution $(0.1 \%$ TritonX-100 in $0.1 \%$ sodium citrate, freshly prepared) at RT. After drying, $50 \mu \mathrm{l}$ TUNEL reaction mixture $(5 \mu \mathrm{l}$ enzyme solution + $45 \mu$ l label solution) was added on top of each coverslips and samples were incubated $60 \mathrm{~min}$ at $37^{\circ} \mathrm{C}$. Coverslips were washed 3 times and incubated with DAPI dye, sealed and visualized by Leica DMi8 inverted microscope (Leica Microsystems, Germany). Quantification of images was done with ImageJ software (NIH Image, NIH Bethesda, USA).

\section{YO-PRO-1/PI staining}

Cells were seeded to 12 -well plates (30,000 cells/well). Chaetocin and TRAIL simultaneous treatments $(100 \mathrm{nM}, 100 \mathrm{ng} / \mathrm{ml}$, respectively) were performed for $6 \mathrm{~h}$. Wells were rinsed once with PBS followed by incubation in $300 \mu \mathrm{l}$ staining solution $(1 \mu \mathrm{M}$ YO-PRO-1 by Invitrogen Cat. No: Y3603, Thermo Fisher, USA and 1:1000 PI $(1 \mathrm{mg} / \mathrm{ml})$ in PBS) for $15 \mathrm{~min}$ at $37^{\circ} \mathrm{C}$ in dark. Each well was visualized, and representative images were taken by Nikon Eclipse TS100 Inverted Fluorescence Microscope (Nikon Instruments Inc., NY, USA). Quantification of images was done with ImageJ software (NIH Image, NIH, Bethesda, USA).

\section{RNA sequencing}

Cells were seeded $(400,000$ cells/well) to 6-well plates. Experimental group consisted of duplicates of untreated control cells and cells treated with chaetocin $(50 \mathrm{nM})$ for $24 \mathrm{~h}$. RNA extraction was performed by Qiagen RNAeasy Mini Kit. Samples were sent to Berkeley University Functional Genomics Laboratory (Berkeley, CA) for sequencing at Illumina Hiseq4000 system to generate $50 \mathrm{bp}$ single-end reads. Detailed methods on library preparation is described in Supplementary Info. Data have been deposited in NCBI's Gene Expression Omnibus, accessible with GEO\# GSE126462. Differentially expressed genes were identified based on negative binomial distribution using DESeq2(v.1.18.1) ${ }^{33}$. Enrichment of gene sets were analyzed using Gene Set Enrichment Analysis (GSEA) software ${ }^{34}$ to obtain enriched hallmark pathways related to drug treatment. 


\section{In vitro ROS detection}

U87MG cells were seeded (300.000 cells/well) in 6well plates. NAC was applied $24 \mathrm{~h}$ prior to and during chaetocin treatment. Chaetocin treatment is started $3 \mathrm{~h}$ before the induction with ROS detection reagent and endured during the loading process, whereas pyocyanin is added right at the induction step. Cells were detached by trypsinization, collected, washed with wash buffer and centrifuged at RT. Cells were induced by loading with ROS/Superoxide detection mix (Abcam, ab139476 kit) supplemented with above mentioned treatments and incubated for $30 \mathrm{~min}$ in the cell culture incubator $\left(37^{\circ} \mathrm{C}, 5 \% \mathrm{CO}_{2}\right)$. Samples were kept on ice and analyzed with Flow Cytometry (BD Biosciences, USA) at FL1-A (green oxidative stress detection reagent) and FL2-A (orange, superoxide detection reagent) channels for 10.000 cells. Compensation correction was made to avoid overlap between green and orange fluorescent signals.

\section{H2AX staining}

U87MG cells were seeded (25,000 cells/well) on glass coverslips in 24-well plates. Upon completion of treatment (simultaneous combinatorial treatment with Chaetocin and TRAIL), wells were washed with PBS (3 times) and cells were fixed using 100\% ice-cold methanol. Cells were washed with PBS (3 times) and then incubated in blocking solution ( $5 \mathrm{ml}$ Triton-X, 7,5 ml FBS, $37.5 \mathrm{ml}$ PBS) for $15 \mathrm{~min}$ at RT. Cells were washed with PBS (3 times) and then incubated in primary antibody (Antiphospho-Histone H2AX Ser139 Antibody, Millipore, 05-636, 1:100 diluted) at RT for $2 \mathrm{~h}$ (or overnight at $4{ }^{\circ} \mathrm{C}$ ). Cells were washed with PBS (3 times) and incubated with secondary antibody (anti-Mouse IgG, Texas Red IR conjugated, 1:100 diluted) for $1 \mathrm{~h}$ at RT. After washing, coverslips were mounted in DAPI on microscope slides and visualized with Leica DMi8 inverted microscope (Leica Microsystems, Germany).

\section{Cloning}

gRNA: In order to deplete the expression of selected genes such as DR5, Casp8, Bid, Casp3, Casp7, Suv39H1, and HMOX1 with CRISPR/Cas9 method, gRNAs were either derived from Gecko v2 library ${ }^{35}$ or designed against functional domains of genes using CCtop tool ${ }^{36}$. All gRNA sequences are presented in Supplementary Table 3. For cloning, top and bottom strands of gRNA against target genes were annealed and used for ligation into pLenti-CRISPR-V2 vector (for HMOX1), pLenti-CRISPR-V1 vector (for SUV39H1) and pLenti-Guide vector (for DR5, Bid, Casp8, Casp3, and Casp7), which was digested by BsmB1 followed by antarctic phosphatase treatment. Ligation was performed at RT for 15 min using Quick
Ligase Kit (Roche, Switzerland) and ligation product was heat shock transformed to competent bacteria Stbl3. After growing and selecting in LB, plasmid isolation and diagnostic digestion was performed by $\mathrm{MN}$ miniprep kit, and plasmids were sent for sequencing. The efficiency of gRNAs was then verified in cells transduced with each vector using T7 Endonuclease Assay, as described in Supplemental Information. Efficient knockout with gRNA occurs within approximately 18 days since Cas 9 activity takes time.

shRNA: shRNA sequences targeting Bcl2 and BclXL were designed using RNAi Codex program ${ }^{37}$. All oligo sequences are listed in Supplementary Table 4. These oligos were PCR-amplified by using following primers having compatible restriction ends with backbone vector, pSMP. F: 5'GATGGCTGCTCGAGAAGGTATATTGCT GTTGACAGTGAGCG-3', R: 5'-CCCTTGAACCTCCT CGTTCGACC-3'. PCR products were cloned into pSMP retro-viral backbone as described ${ }^{38}$. All vectors were verified by sequencing.

Tet-TRAIL vector: DNA sequence producing secreted TRAIL protein was amplified from LV-TRAIL plasmid via primers containing BamHI and $\mathrm{XbaI}$ cut sites and ligated into pENTR1A plasmid (Addgene plasmid \#17398). Then, Gateway cloning was performed to take pLIX_402 Tetinducible lentiviral expression vector (Addgene plasmid \#41394). Vectors were verified by sequencing. The efficiency of the Tet-TRAIL was tested in vitro after transduction of U87MG cells with lentiviruses and treating with different concentrations of Doxycycline (D9891 Sigma-Aldrich, MO, USA).

\section{Viral packaging and transduction}

All lentiviral or retroviral vectors used to transduce GBM cells throughout this study are listed in (Supplementary Table 6) and all viral packaging was performed as described ${ }^{38,39}$. Briefly, on day0, $2.5 \times 10^{6} 293 \mathrm{~T}$ cells were seeded to $10 \mathrm{~cm}$ culture dish with DMEM supplemented with $10 \%$ FBS and $1 \%$ Pen/Strep. Viral plasmid DNA $(2,5 \mu \mathrm{g})$ and packaging plasmids 8.2Dvpr and VSVG $(2,5 \mu \mathrm{g})$ were transfected to cells using FugeneHD (Promega, USA). Next day, media of plate was changed and 48 and $72 \mathrm{~h}$ post transfection, media containing virus was collected. Viral media was aliquoted and stored at $-80^{\circ} \mathrm{C}$. Cells were seeded at desired density and were transduced with virus containing media supplemented with protamine sulfate $(10 \mu \mathrm{g} / \mathrm{ml})$. Sixteen hours post-transduction, viral medium was replaced by fresh media. Transduced cells were selected by Puromycin at a final concentration of $1 \mu \mathrm{g} / \mathrm{ml}$ for 3 days. For constructs in pLenti-Guide backbone, cells were transduced with lentiCas9-Blast vector and selected with Blasticidin for 6 days prior to transduction with gRNAs. 


\section{Patient survival analysis}

Gene expression profiles of "glioblastoma multiforme" (GBM) and "brain lower grade glioma" (LGG) tumors were preprocessed by the unified RNA-Seq pipeline of the Cancer Genome Atlas (TCGA) consortium (https:// portal.gdc.cancer.gov). For both cancer types, HTSeqFPKM files of all primary tumors from the most recent data freeze (i.e., Data Release 14-December 18, 2018) were downloaded, leading to 703 files in total. Metastatic tumors were not included since their underlying biology would be very different than primary tumors. Clinical annotation files of cancer patients were used to extract their survival characteristics (i.e., days to last follow-up for alive patients and days to death for dead patients). For both cancer types, Clinical Supplement files of all patients from the most recent data freeze were downloaded, leading to 1114 files in total. To perform survival analysis using gene expression profiles, only patients with available survival information and gene expression profile were included, which led to a collection of 663 patients in total. The gene expression profiles of primary tumors were first $\log _{2}$-transformed and then $z$-normalized within each cohort before further analysis. The heat maps of gene expression values were based on these $z$-normalized gene expression values. For gene set analyses, 663 samples were grouped into two categories using $k$-means clustering $(k=2)$ on the $z$-normalized gene expression values of all genes included. Kaplan-Meier survival curves of these two groups were then compared. For single gene analyses, 663 samples were first grouped into two categories (i.e., low and high) by comparing each sample's gene expression value against the mean expression value of that particular gene. Kaplan-Meier survival curves of these two groups were then compared. $p$-value obtained from the log-rank test performed on these two survival curves were displayed.

\section{In vivo experiment}

Non-obese diabetic/severe combined immunodeficiency (NOD/SCID) mice housed and cared in appropriate conditions of Koç University Animal Facility were used and all protocols were approved by the institution boards of Koç University. Firefly Luciferase (Fluc) and mCherry expressing stable U87MG cells were generated by viral transduction as described ${ }^{39}$. mCherry expression was validated by fluorescence microscopy and Fluc activity was validated by utilizing in vitro luminescence assay and Synergy Biotek Plate reader. Before implantation, Fluc-mCherry expressing U87MG cells were transduced with Tet-TRAIL lentiviruses. For subcutaneous tumor implantation, $2 \times 10^{6}$ were injected in $100 \mu \mathrm{l}$ PBS per mouse ( $n=5 /$ group) into the flanks of mice. For orthotopic model, $1 \times 10^{5}$ cells were injected in $7 \mu \mathrm{l}$ PBS intracranially using stereotaxic injection, as described ${ }^{40}$.
Tumor development was monitored by repeated noninvasive bioluminescence imaging (IVIS Lumina III) using $150 \mu \mathrm{g} / \mathrm{g}$ of D-Luciferin intraperitoneally. To test the effect of TRAIL and/or chaetocin, mice with established tumors were categorized into four experimental groups and doxycycline $(10 \mathrm{mg} / \mathrm{ml})$ and chaetocin $(20 \mathrm{mg} / \mathrm{kg})$ treatments were performed simultaneously as intraperitoneal injections (twice/week). Two weeks after treatment, mice were sacrificed, and tumors were dissected. Quantification of tumor progression was performed with GraphPad PRISM software (San Diego, CA, USA)

\section{Results \\ Epigenetic compound screen identifies chaetocin as a novel TRAIL sensitizer}

To identify compounds that can sensitize GBM cells to TRAIL, we conducted a chemical screen in U87MG cells using a library composed of compounds targeting different classes of chromatin modifiers ${ }^{31}$. The screen assessed the effects of the inhibitors alone or in combination with a fixed concentration of TRAIL through ATP based cell viability assays (Fig. 1a). DMSO-only treated and untreated cells served as negative controls. On average, compounds alone had minimal effect on cell viability $(98.8 \pm 9.9 \%)$. To determine which compounds to followup, we took into account total variability across all compounds and considered a compound a hit if it reduced cell viability $1 \mathrm{SD}$ or lower $(88.9 \%$ for compound alone and $42.1 \%$ for TRAIL combination). Accordingly, 9 compounds significantly decreased viability (namely; HDAC inhibitors Belinostat, CI-994 and TrichostatinA, HDM inhibitors GSK-J4, JIB-04 and Tranylcypromine; bromodomain inhibitor PFI-1, HMT inhibitor SGC0946 and methyl-lysine reader domain antagonist UNC1215) on their own. The response to TRAIL alone was $62 \pm 0.8 \%$ for control and $65 \pm 1 \%$ for DMSO groups (Fig. 1b). When combined with TRAIL, compounds that decreased viability below 42.1\% were SGC0946, GSK-J4, SAHA, 5-Azacytidine, PFI-1, HASPIN, chaetocin, TrichostatinA and Belinostat (Fig. 1c). After validating the hits from the screen (Supplementary Fig. 1A), we focused on those that did not reveal toxicity on their own but augmented the TRAIL-response of GBM cells. Those compounds were chaetocin, HASPIN, and SAHA. While SAHA, a wellknown HDAC inhibitor, has been previously reported to cooperate with TRAIL ${ }^{41}$ and the antitumor role of protein kinase HASPIN has been established ${ }^{42,43}$, chaetocin has not been studied in relation to TRAIL in GBM. Therefore, we chose to further assess the effects of chaetocin, a fungal metabolite produced by Chaetomium fungal species that has antimicrobial and cytostatic activity ${ }^{44}$. Chaetocin is an unspecific inhibitor of lysine-specific histone methyltransferases including SU(VAR) $3-9^{45}$ and also inhibits the oxidative stress mitigation enzyme 


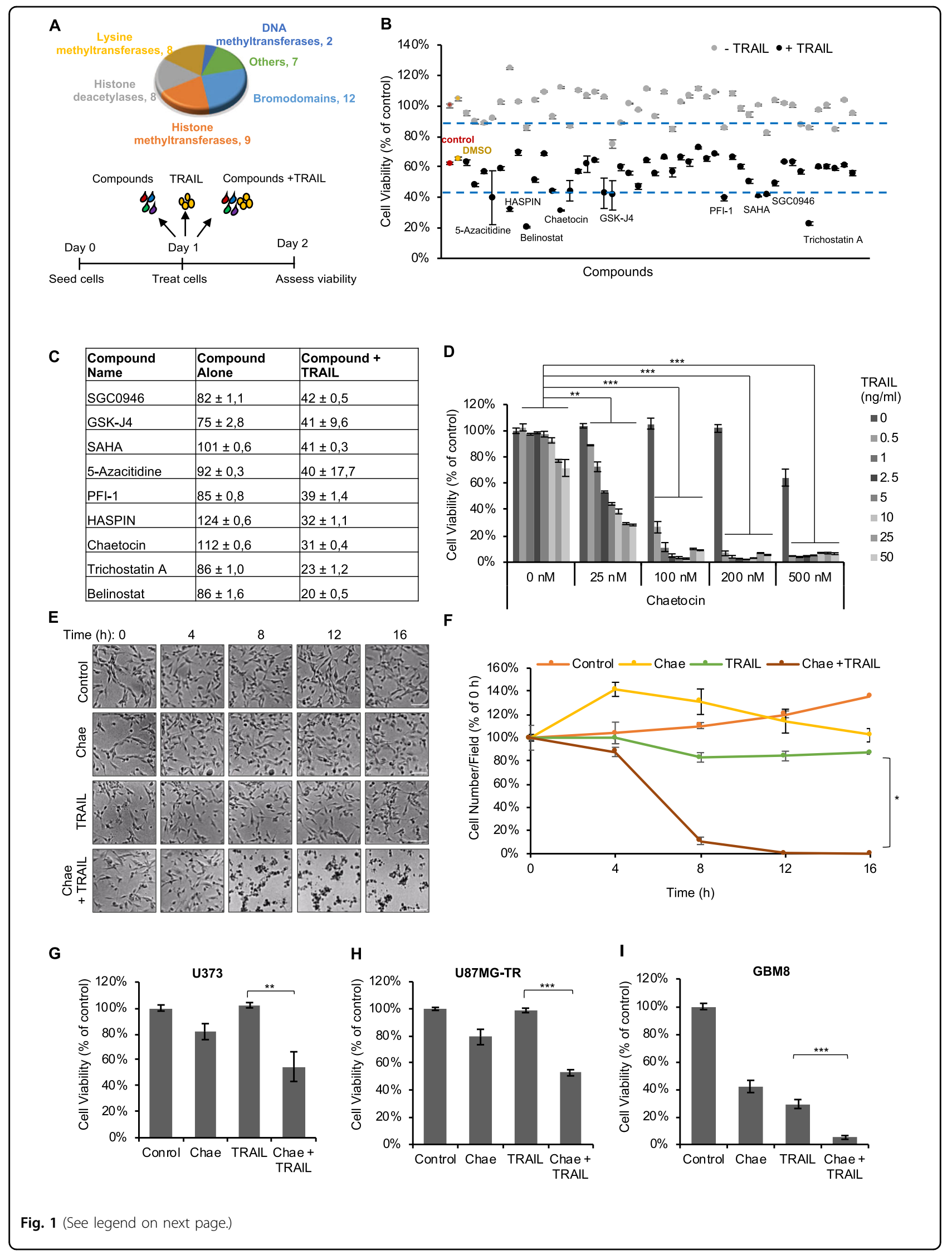


(see figure on previous page)

Fig. 1 Epigenetic compound screen identifies chaetocin as TRAIL sensitizer. a Top: Chemical library composition of inhibitors of chromatin modifier proteins (12 Bromodomain inhibitors, 8 HDAC inhibitors, 9 HMT inhibitors, 8 HDM inhibitors, 2 DNMT inhibitors, 2 kinase inhibitors and 1 HAT inhibitor). Bottom: Schematic diagram of the experimental setup. b Plot of percent cell viability after treatment. Data were normalized to untreated control cells. Dotted lines denote 1 S.D. from \% Mean cell viability upon treatment. Compounds lying below the lower threshold are TRAIL sensitizers. c List of compounds that augmented TRAIL response. $\mathbf{d}$ Viability analyses of U87MG cells showing markedly reduced viability upon Chaetocin and TRAIL combinational treatment at various dosages for $24 \mathrm{~h}$. Data were normalized to untreated control. e Representative snapshot images from live cell imaging of U87MG cells upon chaetocin (100 nM) and TRAlL $(100 \mathrm{ng} / \mathrm{ml})$ combinatorial treatment for $16 \mathrm{~h}$. Scale bar: $100 \mu \mathrm{m}$. $\mathbf{f}$ Quantification of live cell imaging data by ImageJ program through counting live/death cell percentage at each time point. $\mathbf{g}$ Viability analyses of innately TRAIL resistant U373 cells, $\mathbf{h}$ U87MG-TR cells with acquired TRAIL resistance and $\mathbf{i}$ primary GBM cell line GBM8 upon chaetocin and TRAIL combinatorial treatment chaetocin $(100 \mathrm{nM})$ and TRAIL $(100 \mathrm{ng} / \mathrm{ml})$ for $24 \mathrm{~h}$. Data were normalized to untreated control cells $((*),(* *)$, and $(* * *)$ denote $P<0.05, P<0.01$ and $P<0.001$, respectively, two-tailed Student's $t$-test).

thioredoxin reductase- 1 (TrxR1 or TXNRD1) ${ }^{46}$. To assess the potential of chaetocin as a TRAIL sensitizer, we performed viability assays. Accordingly, Chaetocin combination sensitized U87MG cells to TRAIL in a dosedependent manner, even at low doses which did not exert toxicity alone (Fig. 1d). Using CompuSyn software based on Chou-Talalay model for synergy quantification, we calculated combination index $(\mathrm{CI})$ value for Chaetocin and TRAIL (Supplementary Fig. 1B). At effect level (Fa) > 0.5 ; Chaetocin and TRAIL combination yielded CI value smaller than 1 , indicating strong synergism between the two drugs (Supplementary Fig. 1C-D).

To visualize the timing and mode of cell death, we performed live cell imaging on GBM cells. Chaetocin and TRAIL, when applied as single agents were not potent death inducers, however when applied in combination, they induced cell death significantly (Fig. 1e, Supplementary videos 1-4). The observed death involved membrane blebbing, cell shrinkage and formation of apoptotic bodies, as characteristic changes observed during apoptosis. Quantification of the number of cells that remain viable in response to treatment revealed significant cooperation of chaetocin and TRAIL in reducing cell viability (Fig. 1f). As U87MG exhibit only medium sensitivity to TRAIL ${ }^{32}$, we examined the effects of chaetocin in fully TRAIL-resistant cells lines as well. Using a resistant derivative of U87MG, U87MG-TR (manuscript under review) and innately resistant U373 cells, we showed that chaetocin could also sensitize these cells to TRAIL (Fig. 1g, h). This effect was observed in a sensitive primary GBM cell line GBM8 as well (Fig. 1i). Together, these findings suggest that chaetocin is a potent agent to overcome TRAIL resistance and augment TRAIL response of GBM cells.

\section{Combined chaetocin and TRAIL treatment leads to efficient apoptosis of GBM cells}

To address whether the observed death upon combinatorial treatment indeed involves apoptosis, we investigated caspase activity of GBM cells. While chaetocin or TRAIL as single agents only moderately increased Casp $3 / 7$ activity, combinatorial treatment resulted in major elevation of Casp3/7 activity (Fig. 2a, Supplementary Fig. 2A-B). Similarly, enhanced cleavage of both initiator (Casp8) and effector (Casp9, Casp3) caspases were evident in combinatorial treatment, as revealed by western blotting. Furthermore, significant truncation and activation of Bid, a link between extrinsic and intrinsic apoptosis, was detected when GBM cells were treated with both chaetocin and TRAIL. Finally, as an important hallmark of apoptosis, cleavage of Poly (ADP-ribose) polymerase-1 (PARP) was also markedly enhanced upon combinatorial treatment (Fig. 2b).

To examine the apoptotic features of GBM cells, we performed TUNEL assay, which detects fragmented DNA generated during apoptosis ${ }^{47}$ and showed TUNELpositive cells were significantly more abundant in GBM cells sensitized to TRAIL through chaetocin (Fig. 2c, d). Similarly, in a fluorescence dye-based "live/dead assay", we observed significant increases in the percentage of apoptotic cells upon combinatorial treatment (Fig. 2e, f). These results were supported by flow cytometric analysis of AnnexinV-positive and PI-positive cells, where the presence of enhanced early and late apoptotic cells were evident with both chaetocin and TRAIL treatment (Fig. 2g, h, Supplementary Fig. 2C-D) indicating that chaetocin and TRAIL cooperate to induce apoptosis in GBM cells.

To further validate these findings, we investigated the functional effect of caspase activation using general caspase inhibitor Z-VAD-FMK. Accordingly, the inhibitor interfered with TRAIL sensitizing effect of chaetocin and markedly reduced cell death (Fig. 2i, Supplementary Fig. 2E). Next, we generated CRISPR-Cas9 mediated ablation of apoptosis-mediator proteins DR5, Casp8, Bid, Casp7, and Casp3 in U87MG cells (Fig. 2j). While individual knockout of the major components of extrinsic apoptosis pathway, DR5 and Casp8, recovered the cell death induced by chaetocin and TRAIL, the knockout of either Casp3 or Casp7 alone were not sufficient to recover the chaetocin induced TRAIL sensitization (data not shown). 

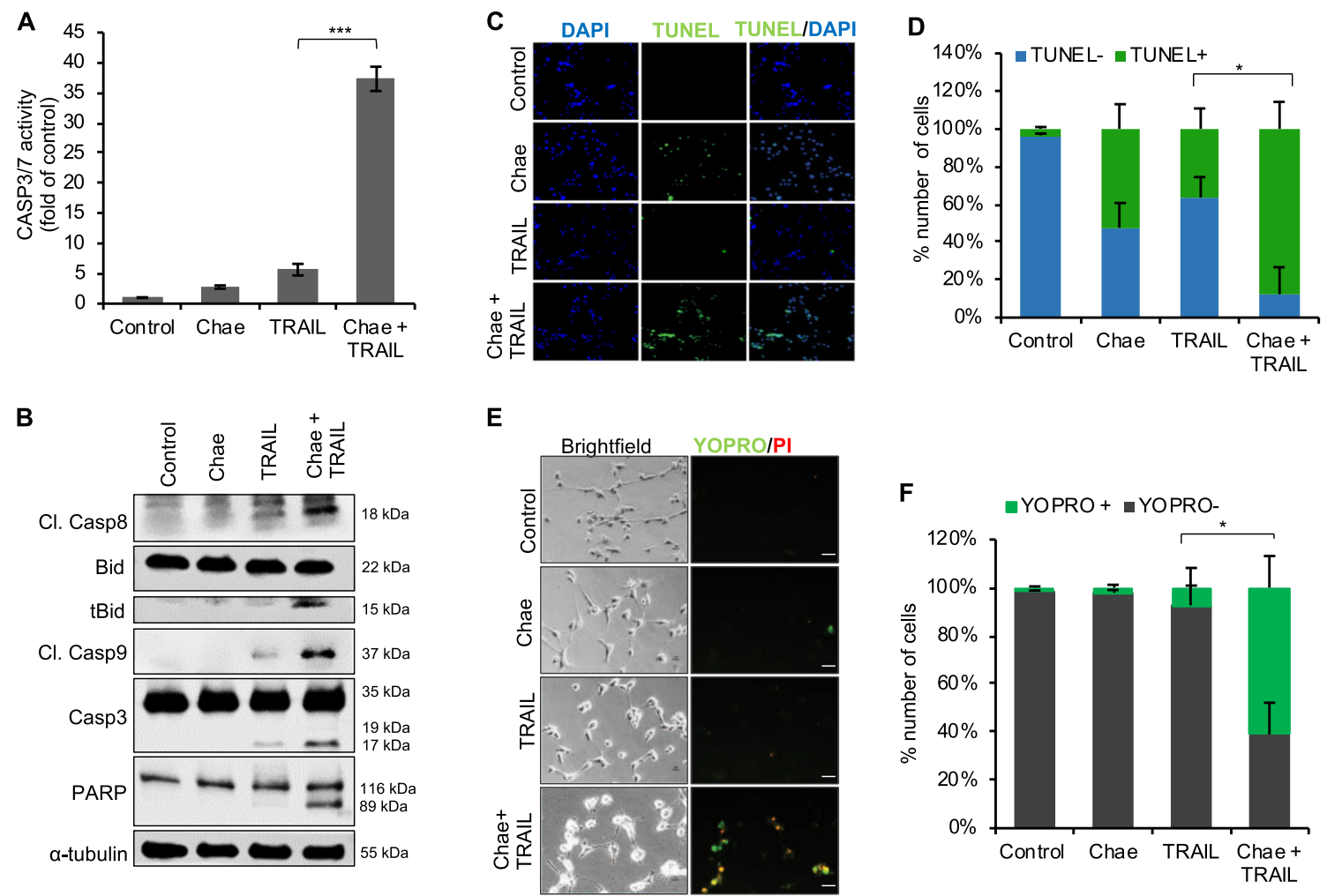

G

H
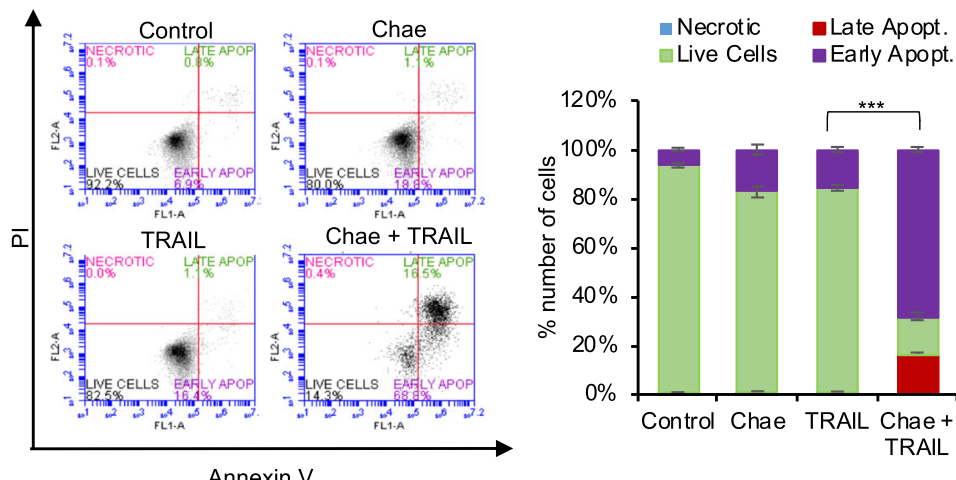

I

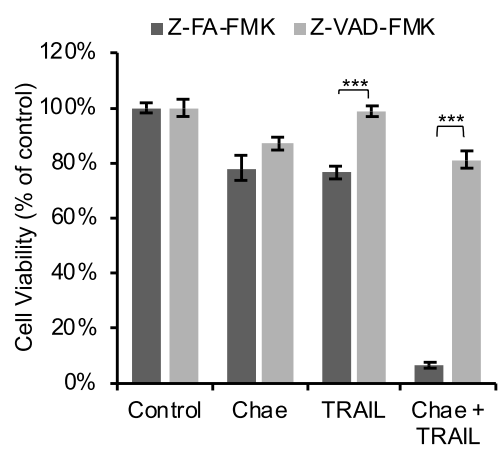

J

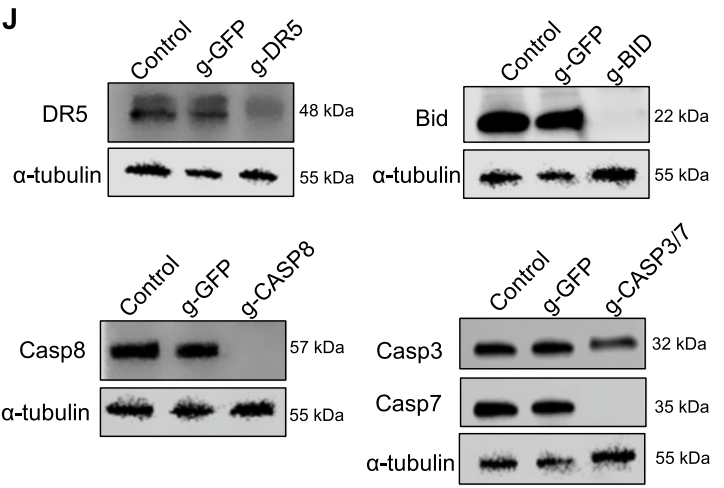

K

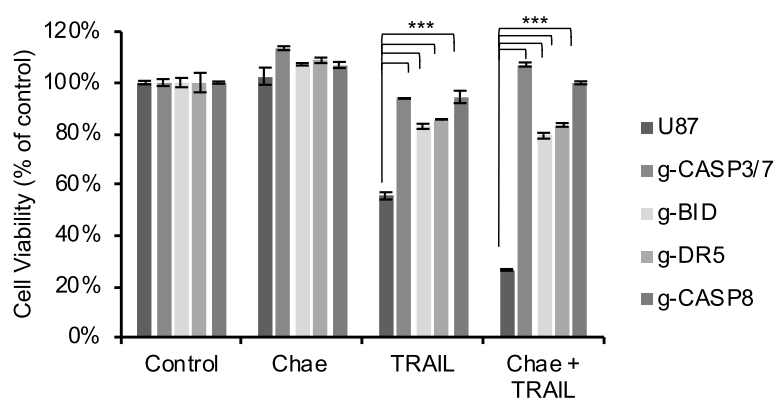

Fig. 2 (See legend on next page.) 
(see figure on previous page)

Fig. 2 GBM cells display augmented apoptotic response upon chaetocin and TRAIL combinatorial treatment. a Caspase-3/7 activity analyses of U87MG cells upon chaetocin (100 nM) and TRAlL $(100 \mathrm{ng} / \mathrm{ml})$ combinatorial treatment. Data were normalized to untreated control cells. b Western blot analyses of U87MG cells for cleaved Casp8, Bid, t-Bid, Casp3 and PARP after pretreatment with chaetocin (100 nM for $24 \mathrm{~h}$ ) followed by $6 \mathrm{~h}$ TRAll $(100 \mathrm{ng} / \mathrm{ml})$ treatment. a-tubulin was shown as protein loading control. c Terminal deoxynucleotidyl transferase dUTP nick end labeling (TUNEL) assay on U87MG cells showing increased DNA fragmentation upon chaetocin (100 nM) and TRAIL (100 ng/ml) combinatorial treatment for $24 \mathrm{~h}$. Blue: DAPI staining nuclei, Green: TUNEL (+) cells. Scale bar: $100 \mu \mathrm{m}$. d Quantification of TUNEL staining by ImageJ program through counting TUNEL (+) cells with green fluorescence. e YO-PRO-1 and PI staining upon chaetocin $(100 \mathrm{nM})$ and TRAIL $(100 \mathrm{ng} / \mathrm{ml})$ combinatorial treatment of U87MG cells for $24 \mathrm{~h}$. Green: YO-PRO-1 staining apoptotic cells, Red: PI staining dead/necrotic cells. Scale bar: $200 \mu \mathrm{m}$. f Quantification of YO-PRO-1/PI staining by ImageJ program through counting green and red fluorescence positive cells. $\mathbf{g}$ Flow cytometric analysis of Annexin V/PI stained U87MG cells upon chaetocin $(100 \mathrm{nM})$ and TRAIL $(100 \mathrm{ng} / \mathrm{ml})$ combinatorial treatment for $24 \mathrm{~h}$. $\mathbf{h}$ Quantification of flow cytometry data showing marked increase in apoptotic cell populations upon combinatorial treatment. Data were normalized to total number of cells under each condition. $\mathbf{i}$ Cell viability analysis U87MG cells pretreated with caspase inhibitors $(20 \mu \mathrm{M}$ for $24 \mathrm{~h}$ ) followed by chaetocin ( $100 \mathrm{nM})$ and TRAlL $(100 \mathrm{ng} / \mathrm{ml})$ treatment for $24 \mathrm{~h}$ in presence of inhibitors. Z-FA-FMK: negative control, Z-VAD-FMK: general caspase inhibitor. $\mathbf{j}$ Western blot analyses of U87MG cells showing individual stable CRISPR knockouts of DR5, BID, and Casp8, as well as double knock out Casp3/7 genes. GFP targeting guide RNA (g-GFP) was used as negative control for CRISPR assay. a-tubulin was shown as protein loading control. $\mathbf{k}$ Viability analysis of CRISPR edited U87MG cells upon combinatorial treatment with chaetocin $(100 \mathrm{nM})$ and TRAlL $(100 \mathrm{ng} / \mathrm{ml})$ for $24 \mathrm{~h}$. Data were normalized to untreated control. $\left(\left(^{*}\right)\right.$ and $\left(^{* * *}\right)$ denote $P<0.05$ and $P<0.001$, respectively, two-tailed Student's $t$-test).

When both effector caspases were simultaneously ablated, there was a recovery in the response of GBM cells. Similarly, the reduction of Bid levels led to effective recovery of cell viability upon combinatorial treatment (Fig. 2k). Taken together, our data demonstrate that chaetocin-induced TRAIL sensitization involves the activation of major apoptotic machinery in GBM cells.

\section{Chaetocin effectively sensitizes GBM cells to other pro- apoptotic agents, such as FasL and BH3 mimetics}

To evaluate whether chaetocin mediated apoptotic sensitization is exclusive to TRAIL or whether it can be a general sensitizer for apoptosis, we explored the effect of chaetocin in combination with further pro-apoptotic agents. Chaetocin effectively sensitized GBM cells, as well as U87MG-TR cells (Supplementary Fig. 3A) to FasL, another extrinsic apoptosis ligand (Fig. 3a-d, Supplementary Videos 5-8), as revealed by end-point cell viability assays (Fig. 3a, b) and live cell imaging (Fig. 3c, d). In addition, depletion of Casp8, but not DR5, recovered chaetocin mediated sensitization to FasL (Supplementary Fig. 3B). The effect of chaetocin was also tested in combination with BH3 mimetics ABT263 (Bcl2 and BclXL dual inhibitor ${ }^{48}$ ) and WEHI539 (BclXL inhibitor $\left.{ }^{49}\right)$, which are intrinsic apoptosis inducers. Chaetocin was found to be a strong sensitizer against these intrinsic apoptosis inducers (Fig. 3e-h, i-l and Supplementary Fig. 4A-B, Supplementary Videos 9-12 and 13-16). Taken together, these results show that chaetocin cooperated with several apoptotic agents to induce apoptosis in GBM cells.

\section{Manipulation of the intrinsic apoptosis machinery regulates the chaetocin-mediated TRAIL sensitization}

Intrinsic apoptosis ultimately leads to reduction of mitochondrial integrity ${ }^{50}$, where release of Cytochrome C is regulated by the expression and activity of anti- apoptotic Bcl2 and BclXL proteins. Following up on our findings that chaetocin cooperates with $\mathrm{Bcl} 2 / \mathrm{BclXL}$ inhibitors (Fig. 3e-l), we further examined whether genetic manipulation of $\mathrm{Bcl} 2$ and/or BclXL could change the chaetocin-mediated TRAIL sensitization in GBM cells. Endogenous expression of BclXL, but not Bcl2 levels were significantly affected by chaetocin treatment (Fig. 4a). In a gain-of-function approach, we overexpressed Bcl2 or $\mathrm{BclXL}$ using retroviral vectors that co-expressed GFP (or GFP alone as controls) (Fig. 4b-d). Bcl2 or BclXL expression rendered U87MG cells more resistant to apoptosis induced both by TRAIL-only or combinatorial treatment (Fig. 4e). Conversely, in a loss-of-function approach using shRNA vectors, BclXL expression was efficiently downregulated at the mRNA and protein level (Fig. $4 \mathrm{f}-\mathrm{g}$ ) which led to further augmentation of TRAIL sensitization in U87MG cells (Fig. 4h), as well as reducing TRAIL resistance in the fully resistant U373 cells (Supplementary Fig. 5). Taken together, these results show that $\mathrm{Bcl} 2 / \mathrm{BclXL}$ play critical roles in chaetocin-mediated TRAIL sensitization in GBM cells which emphasized the active role of mitochondria in sensitization process.

\section{Chaetocin-induced global transcriptome changes reveal the alteration of important hallmarks of cancer}

Chaetocins' potency as general apoptosis-sensitizer prompted us to check its effect on apoptosis related gene expression. In U87MG cells, chaetocin positively modulated the expression of pro-apoptotic genes such as PUMA, NOXA, HRK, BIM, BAD, DR4, CASP3, and $C A S P 7$, whereas downregulated anti-apoptotic genes such as CIAP1, CIAP2, and MCL1 (Supplementary Fig. 6A). We then performed global transcriptional profiling using RNA sequencing (RNAseq) to analyze the chaetocinmediated changes at the whole transcriptome. A volcano plot for fold-changes in gene expression illustrated that 
A

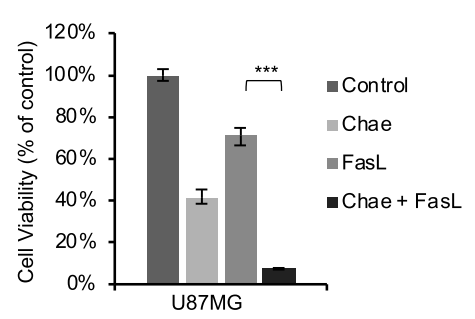

C

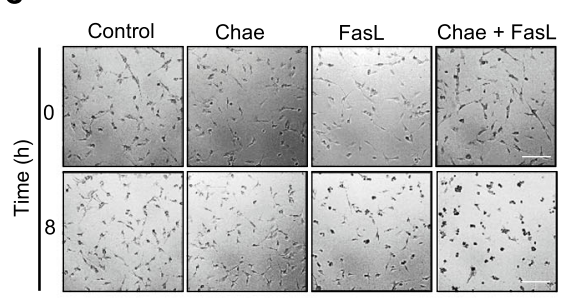

E

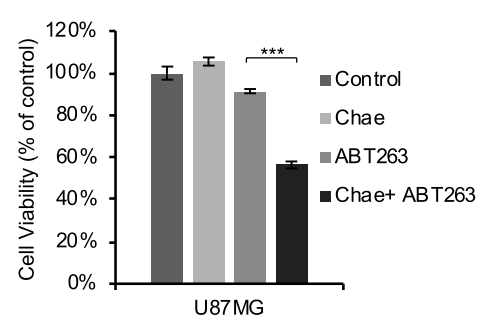

G

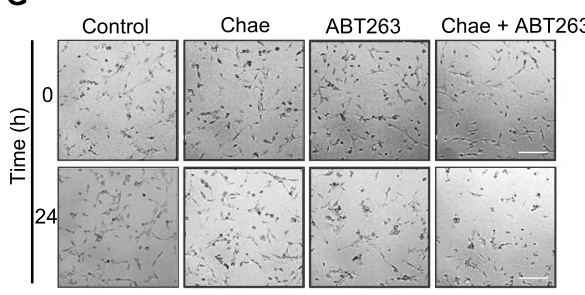

1

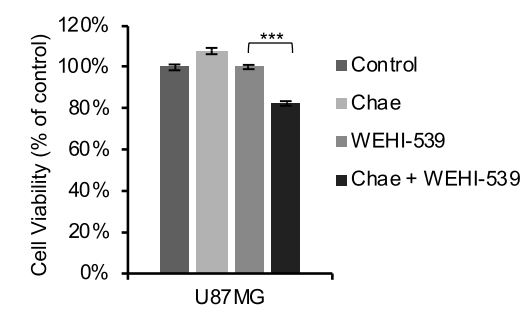

K

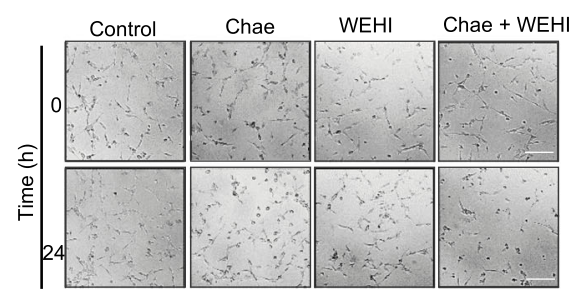

B
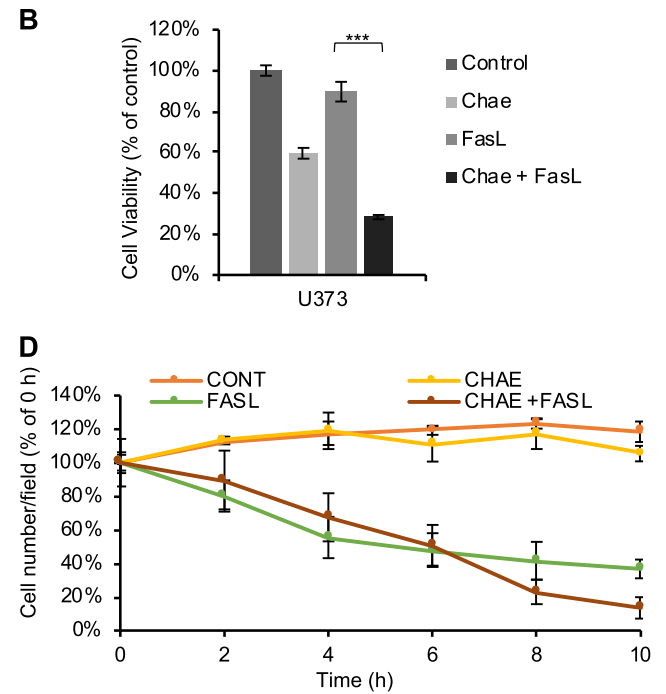

$\mathbf{F}$
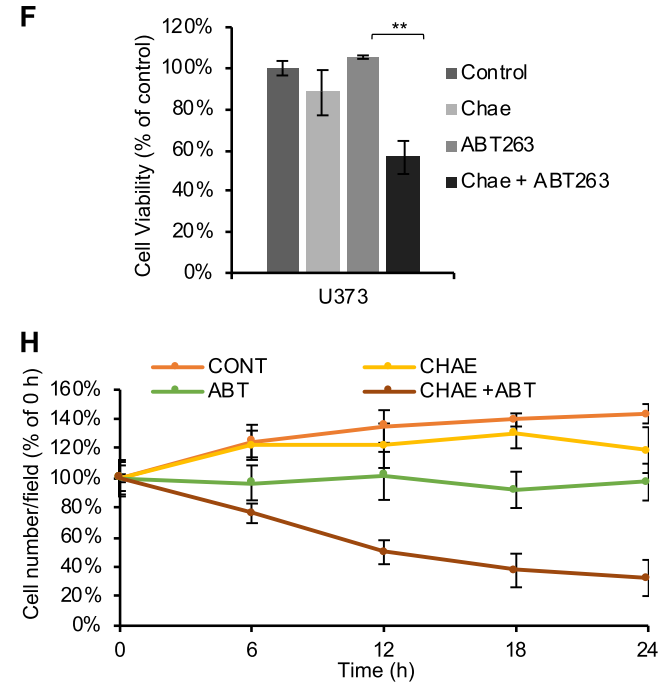

J
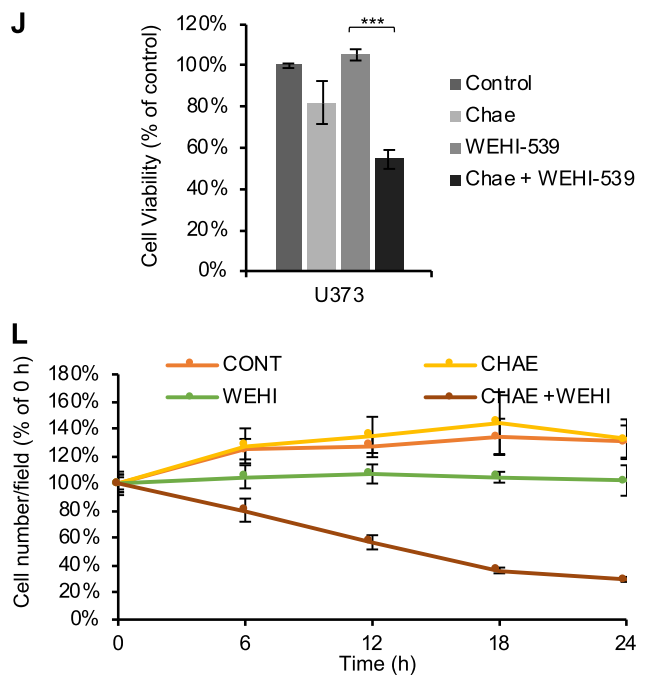

Fig. 3 (See legend on next page.) 
(see figure on previous page)

Fig. 3 Chaetocin effectively sensitizes GBM cells to other pro-apoptotic agents, FasL and BH3 mimetics. a, b Viability analyses of U87MG (a) and U373 (b) cells showing markedly reduced viability upon combinatorial treatment with chaetocin (100 nM) and FasL (100 ng/ml) for $24 \mathrm{~h}$. Data was normalized to untreated control. c Representative snapshot images from live cell imaging of U87MG cells upon chaetocin (100 nM) and FasL $(200 \mathrm{ng} / \mathrm{ml})$ combinatorial treatment for $10 \mathrm{~h}$. Scale bar: $200 \mu \mathrm{m}$. d Quantification of live cell imaging by ImageJ program through counting live/dead cell percentage at each time point. e, $\mathbf{f}$ Viability analyses of U87MG (e) and U373 (f) cells showing significantly reduced viability upon combinatorial treatment with chaetocin $(100 \mathrm{nM})$ and ABT263 $(1 \mu \mathrm{M})$ for $24 \mathrm{~h}$. g Representative snapshot images from live cell imaging of U87MG cells upon chaetocin $(100 \mathrm{nM})$ and ABT263 $(1 \mu \mathrm{M})$ combinatorial treatment for $24 \mathrm{~h}$. Scale bar: $200 \mathrm{\mu m}$. h Quantification of live cell imaging by Image jprogram through counting live/dead cell percentage at each time point. $\mathbf{i}$, $\mathbf{j}$ Viability analyses of U87MG (i) and U373 (j) cells showing significantly reduced viability upon combinatorial treatment with chaetocin (100 nM) and WEHI-539 $(1 \mu \mathrm{M})$ for $24 \mathrm{~h}$. k Representative snapshot images from live cell imaging of U87MG cells upon chaetocin (100 nM) and WEHI-539 $(1 \mu \mathrm{M})$ combinatorial treatment for $24 \mathrm{~h}$. Scale bar: $200 \mu \mathrm{m}$ I Quantification of live cell imaging by ImageJ program through counting live/dead cell percentage at each time point. $\left(\left(^{* *}\right)\right.$ and $\left(^{* * *}\right)$ denote $P<0.01$ and $P<0.001$, respectively, two-tailed Student's $t$-test).

373 genes were up-regulated and 478 genes were downregulated significantly $(\mathrm{FDR}<0.05)$ upon $24 \mathrm{~h}$ treatment with a low dose $(50 \mathrm{nM})$ chaetocin (Fig. 5a). Changes in the expression of top scoring genes (HMOX1, MLC1, ARL14EPL, ANO8, ITGA2, ITGA11, and TENM2) were validated by qPCR (Fig. 5b, c).

We performed Gene Set Enrichment Analysis (GSEA) ${ }^{34}$ and observed that E2F targets, UV response up, G2M checkpoint, ROS and p53 pathways were among top positively regulated, and EMT, UV-response down, protein secretion and oxidative phosphorylation pathways were among top negatively regulated hallmark pathways (Fig. 5d, e, Supplementary Fig. 7). The heatmaps of genes positively contributing to each enrichment plot revealed significant differences in the expression patterns of UV-response up, p53 and ROS pathway (Fig. 5f). To validate the implications from the GSEA data, we tested the effect of chaetocin on cell cycle distribution (as an output for G2-M checkpoint) and cellular invasion (as output for EMT deregulation) (Supplementary Fig. 8A-B). PI staining revealed cell cycle arrest induction with a significant decrease in the $S$ phase and an increase in G2/M phase following chaetocin treatment in U87MG and U373 cells. Spheroid invasion assay to measure the invasive ability of GBM cells showed a reduction of dispersal upon chaetocin treatment, supporting the negative effect of chaetocin on EMT. ROS was higher upon chaetocin treatment, supporting the earlier findings on chaetocin mediated ROS induction ${ }^{51}$. As expected, the ROS scavenger N-acetyl-L-cysteine (NAC) reduced the level of ROS generated by chaetocin (Fig. 5g). Further evidence for chaetocin-mediated induction of the ROS pathway and its role during apoptosis is elevated expression levels of antioxidant genes such as TXNRD1, GCLM, and NQO1 (Fig. 5h) and pro-apoptotic mediators such as $F A D D, C A S P 3$, and BIM, which could be blocked with NAC treatment (Supplementary Fig. 6B). Chaetocininduced changes in expression levels of other genes such as ARL14EPL and ANO8 were also ROS-dependent (Fig. 5i, Supplementary Fig. 9A, B).

\section{Chaetocin mediated apoptosis sensitization of GBM cells is through ROS generation and consequent DNA damage induction}

To assess the role of ROS in chaetocin mediated apoptosis sensitization, we performed cell viability assays in the presence of NAC. Indeed, NAC treatment completely abolished chaetocin-mediated sensitization to TRAIL (Fig. 6a), to FasL (Fig. 6b) and to BH3 mimetic (Fig. 6c) in GBM and U87MG-TR cells (Supplementary Fig. 10), where PARP and Casp3 cleavage induced by chaetocin and TRAIL treatment was reduced in the presence of NAC (Fig. 6d).

Since ROS is general DNA damage inducer, we examined the role of chaetocin treatment on DNA damage. We analyzed canonical markers of DNA damage such as phospho-H2AX foci formation. Accordingly, $\mathrm{YH} 2 \mathrm{AX}$ staining revealed increased DNA damage by prolonged exposure to chaetocin, which could be blocked by NAC treatment (Fig. 6e, f). We observed expression changes of DNA damage related genes; including mismatch repair (MSH2, MSH6, KU70, and EXO2) and base excision repair (BRCA1 and BRCA2) (Fig. 6g).

As p53 activation was one of the top enriched gene sets from GSEA, we measured p53 protein levels and observed accumulation of $\mathrm{p} 53$ protein in chaetocin treated cells in a ROS-dependent manner (Fig. 6h). The relationship between chaetocin treatment, p53 and TRAIL sensitization was further evaluated using a p53 reporter system in HCT116 colon cancer cells (Supplementary Fig. 11A, B). Also, p53 knockout rendered HCT116 cells slightly resistant to chaetocin-mediated TRAIL sensitization (Supplementary Fig. 11C). NUTLIN, a well-studied MDM2 antagonist and p53 activator $^{52}$ sensitized U87MG cells to TRAIL, providing further evidence for p53 in the chaetocin-induced apoptotic process (Fig. 6i). To rule out the changes in the senescence state due to high p53 activity upon chaetocin treatment, we performed X-gal staining revealing no changes in senescence (Supplementary Fig. 12). 


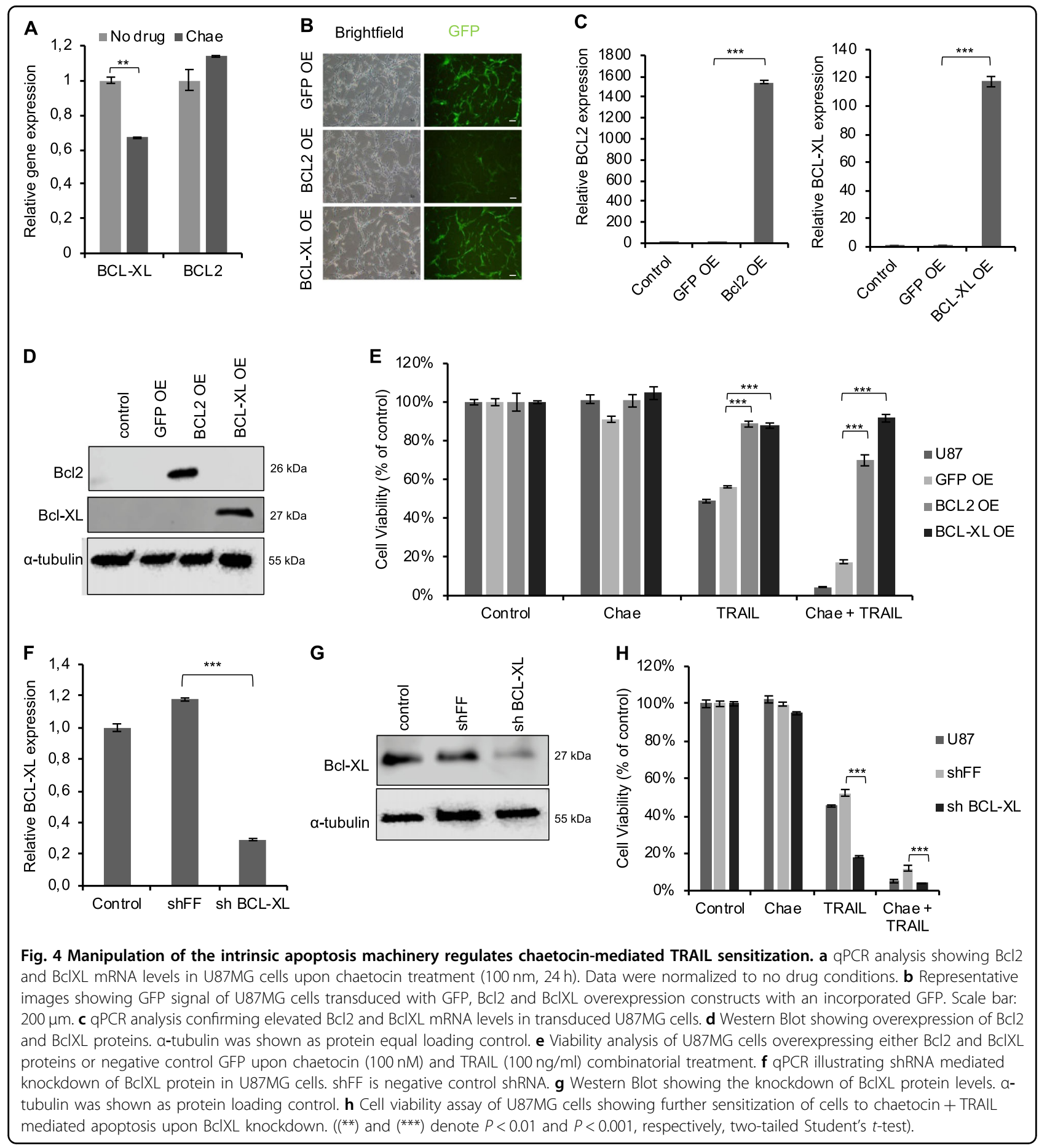

\section{Heme Oxygenase 1 (HMOX1) regulates chaetocin-induced apoptotic sensitization}

Enrichment of UV response, ROS, and p53 as hallmark pathways by GSEA led us to examine whether these chaetocin-induced changes can be recognized in the context of clinical information. We curated a list of genes that were significantly altered within the UV response, ROS, and p53 gene sets and correlated them with glioma patient survival using available TCGA data of GBM and lower grade glioma patient data. We first grouped a total of 663 patient samples into two categories using $k$-means clustering $(k=2)$ on the $z$-normalized gene expression values. Comparing the Kaplan-Meier survival curves of these two groups, we observed a significant clustering and survival difference between the groups (Fig. 7a, b). Heme oxygenase1 (HMOX1) was among the top most 
A

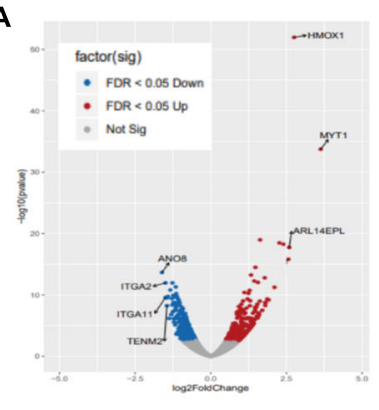

D

Normalized Enrichment Score (NES)

\begin{tabular}{lllll}
-4 & -2 & 0 & 2 & 4 \\
\hline
\end{tabular}

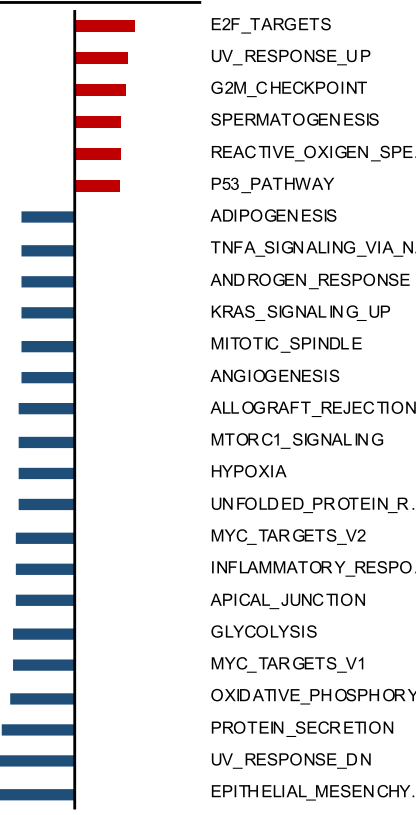

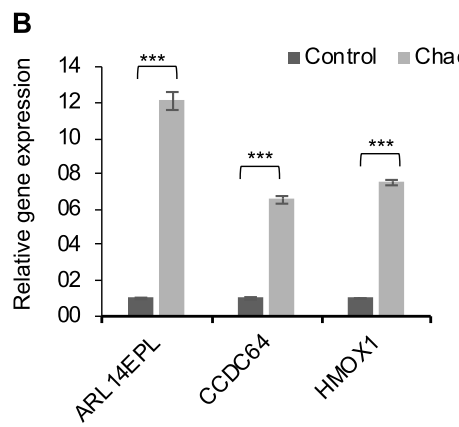

E
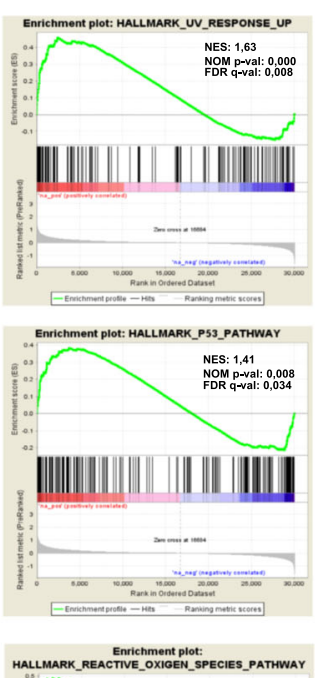

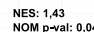

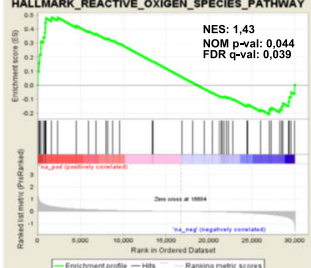

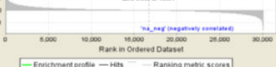

C

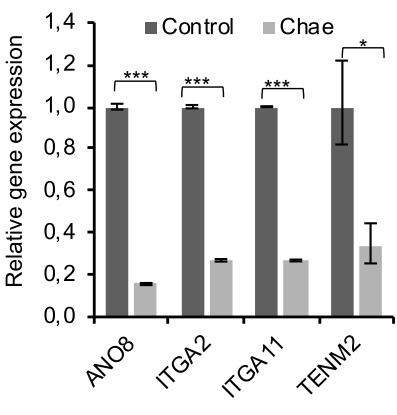

$\mathbf{F}$

UV Response-Up Gene Set

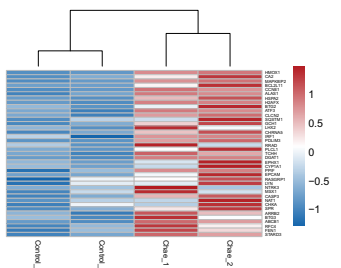

P53 Pathway Gene Set

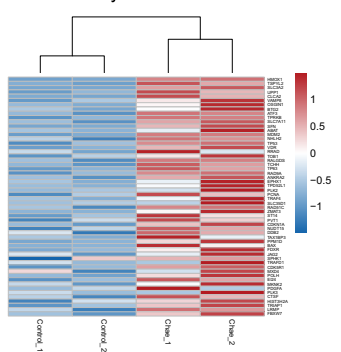

ROS Pathway Gene Set
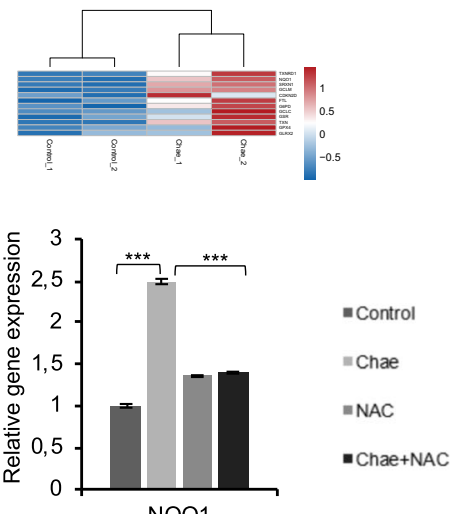

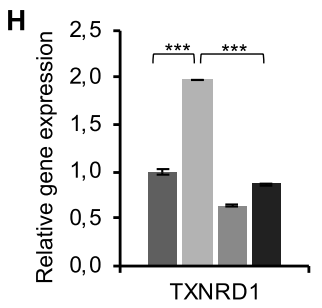

I

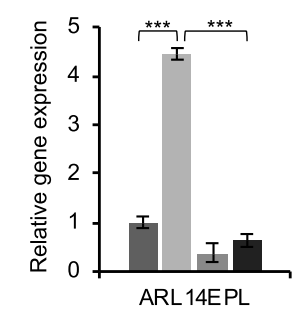

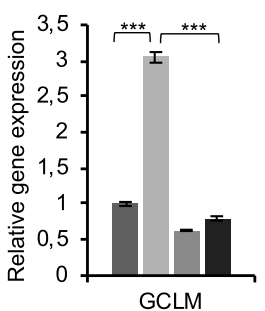

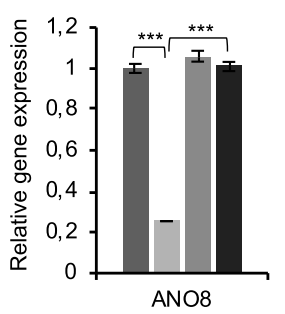

- Control

"Chae

$=$ NAC

- Chae+NAC

Fig. 5 (See legend on next page.) 
(see figure on previous page)

Fig. 5 Chaetocin-induced global transcriptome changes reveal the alteration of important hallmarks of cancer. a Volcano plot of RNA sequencing data showing significantly $(p<0.05)$ up and down regulated genes by chaetocin $(50 \mathrm{nM}, 24 \mathrm{~h})$ based on their log 2 transformed expression data with false discovery rate (FDR) threshold of 0.05. b-c qPCR validation of top 4 upregulated (MLC1, ARL 14EPL, HMOX1, CCDC64) (b) and downregulated (ANO8, ITGA2, ITGA11, TENM2) (c) genes obtained from RNAseq analysis. Data were normalized to untreated control. d Graph represents Gene Set Enrichment Analysis (GSEA) results pointing out chaetocin mediated positively and negatively enriched hallmark pathways based on their Normalized Enrichment Score (NES). e Representative enrichment plots for hallmark UV response-up, p53 and reactive oxygen species pathways. $\mathbf{f}$ Heatmaps of genes listed under UV response-up, p53 and ROS pathways from GSEA revealing significantly upregulated genes upon chaetocin treatment. Expression data were normalized to control condition and log 2 transformed $(p<0.05)$. g DCFDA flow cytometric analysis of ROS generation in U87MG cells treated with chaetocin in the presence or absence of N-acetyl-cysteine (NAC). $\mathbf{h}$ qPCR analysis showing that chaetocin treatment $(100 \mathrm{~nm}, 24 \mathrm{~h})$ upregulated TXNRD1, GCLM, and NQO1 gene levels in ROS-dependent manner. Data were normalized to no drug conditions. i qPCR analysis showing modulation of ARL14EPL and ANO8 gene levels by chaetocin treatment $(100 \mathrm{~nm}, 24 \mathrm{~h})$ in ROS-dependent manner. Data were normalized to Control conditions. ( $\left({ }^{*}\right)$ and $\left(^{* * *}\right)$ denote $P<0.05$ and $P<0.001$, respectively, two-tailed Student's $t$-test).

upregulated gene both by p53 and UV (Fig. 5f) and RNAseq data. HMOX1 is an essential enzyme for heme catabolism $^{53}$. HMOX1 cleaves heme to form biliverdin and carbon monoxide, which exhibit anti-oxidant and anti-inflammatory functions, respectively ${ }^{53}$. Targeting HMOX1 was previously shown to be an effective approach to overcome therapy resistance of hormonerefractory prostate cancer ${ }^{54}$, urothelial and pancreatic cancers $^{55,56}$. HMOX1 expression levels, when analyzed alone, was inversely correlated with glioma patient survival, although not highly significant (Fig. 7c). Since the expression of HMOX1 was significantly modulated by chaetocin (Fig. 7d) we asked whether HMOX1 could be within the regulatory axis during sensitization of GBM cells to TRAIL. We ablated HMOX1 in U87MG cells by CRISPR/Cas9 (Supplementary Fig. 13). Cells that lost HMOX1 expression were more sensitive to TRAIL and combinatorial treatments, again highlighting a critical role for ROS formation (Fig. 7e).

Chaetocin is an unspecific inhibitor of histone methyltransferases, including the H3K9 histone methyltransferase SUV39H1. In addition to its direct inhibition by chaetocin, SUV39H1 was previously shown to be indirectly modulated by cellular ROS produced by chaetocin ${ }^{57}$. We wondered whether the observed TRAIL sensitization is modulated through SUV39H1 inhibition. We generated SUV39H1 knockout U87MG cells (Supplementary Fig. 14A) and checked their TRAIL response. Depletion of SUV39H1 failed to sensitize cells further to apoptosis and rendered them slightly more resistant to TRAIL (Supplementary Fig. 14B). H3K9me(3) levels remained unchanged upon chaetocin treatment indicating that SUV39H1 inhibition is not the root cause for the proapoptotic effects of chaetocin (Supplementary Fig. 14C).

\section{Chaetocin and TRAIL treatments cooperate to reduce tumor growth in vivo}

To explore the efficacy of TRAIL sensitization by chaetocin in vivo, we examined subcutaneous (subQ) and orthotopic xenograft models of U87MG cells expressing firefly luciferase (Fluc) and mCherry (Fig. 8a). To supply tumors with TRAIL on-site, we developed tetracyclineinducible TRAIL vector, whose presence on its own was not toxic to U87MG cells. However, with doxycycline (Dox) treatment, TRAIL secretion was sufficient to markedly reduce U87MG cell viability and tumor growth (Supplementary Fig. 15A-C). In the subcutaneous model, Dox and chaetocin treatments were performed simultaneously and tumor growth was observed over 2 weeks (Fig. 8b). Chaetocin + TRAIL treatment attenuated subcutaneous tumor growth faster in comparison to the TRAIL only group, which was most notable right after treatment (d15); but overall effects of the TRAIL and combinatorial treatments were similar at d27 (Fig. 8c-e). Similarly, intracranial tumor volumes decreased more rapidly in combination treatment group at $\mathrm{d} 15$ though the effects became similar at day 27 (Fig. 8f, g). Representative subcutaneous tumors resected from sacrificed mice are illustrated (Supplementary Fig. 15D). Together, these results suggest that chaetocin and TRAIL combination might serve as efficient therapies for GBM models.

\section{Discussion}

In this study, we interrogated the effects of epigenetic modifying compounds on GBM cell apoptosis in a screening approach and identified chaetocin as a novel sensitizer for apoptotic therapies in GBM cells. Our study explored the chaetocin-induced global effects and sensitizing ability in GBM cells. We showed that the effects of chaetocin on GBM cell apoptosis are unrelated to the alleged effect of chaetocin as SUV9H1 inhibitor; but are through generation of ROS and DNA damage induction leading to a p53 induced pro-apoptotic program. Furthermore, we demonstrated that chaetocin effectively cooperates with TRAIL, FasL, and BH3 mimetics ABT263 and WEHI539 to induce apoptosis in GBM cells. Finally, chaetocin and TRAIL combination treatment revealed efficacy in reducing tumor growth in vivo.

In the screen that involved chemical probes against chromatin modifiers, we identified HDAC inhibitors 


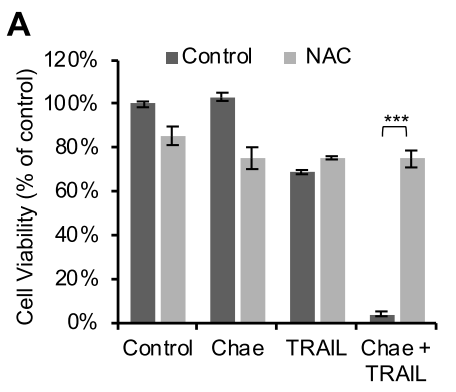

D

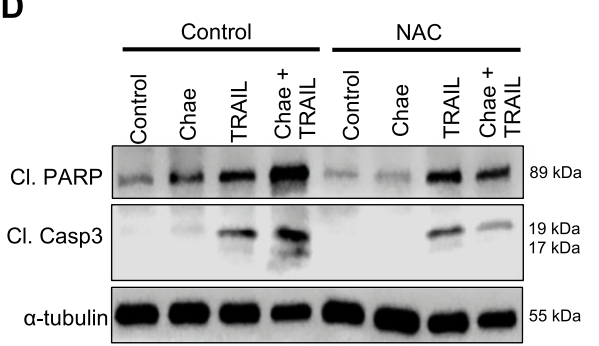

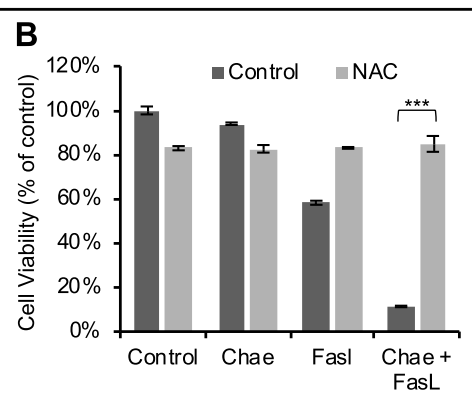

E

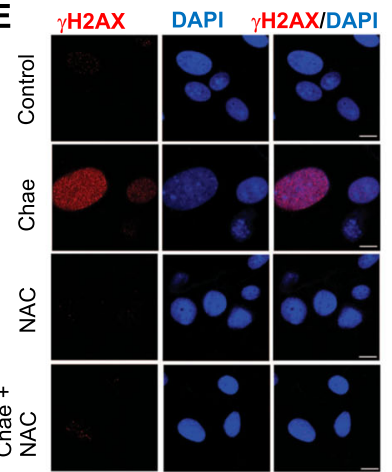

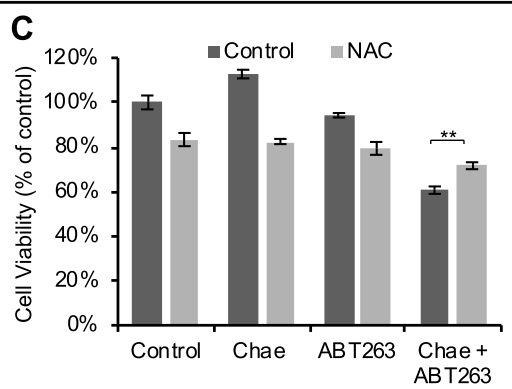

$\mathbf{F}$

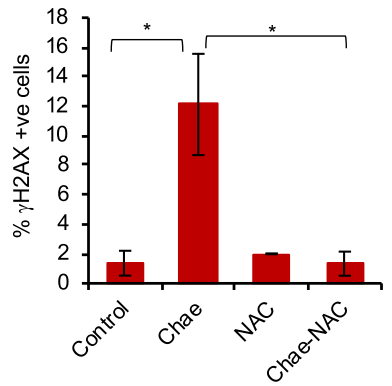

H
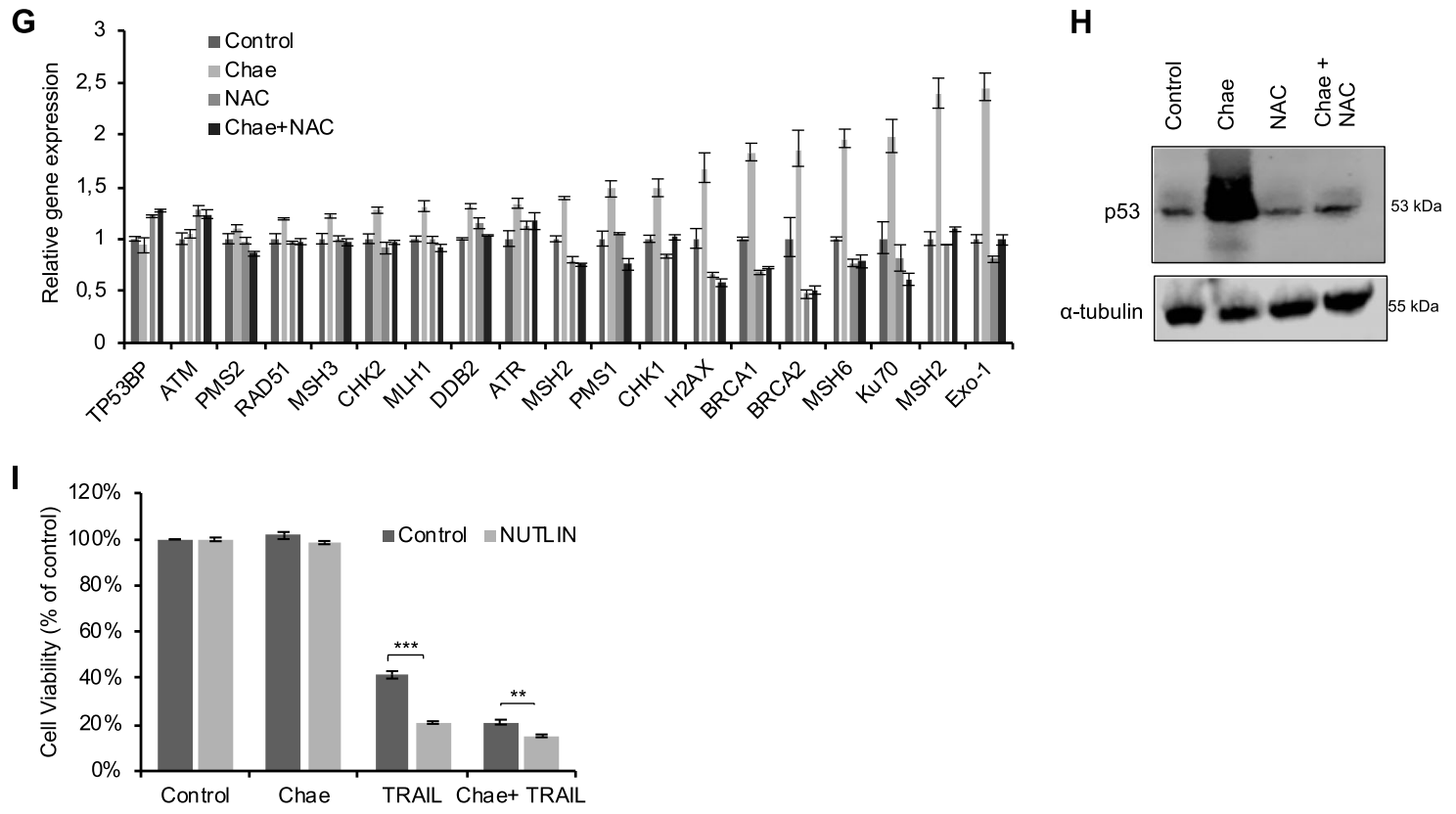

Fig. 6 Chaetocin mediated apoptosis sensitization of GBM cells is through ROS generation and consequent DNA damage induction. a Viability analysis of chaetocin and TRAlL treated cells $(100 \mathrm{nM}, 100 \mathrm{ng} / \mathrm{ml}$, respectively for $24 \mathrm{~h})$ in presence and absence of NAC (10 $\mu \mathrm{M})$. b Viability analysis of chaetocin and FasL treated cells $(100 \mathrm{nM}, 100 \mathrm{ng} / \mathrm{ml}$, respectively for $24 \mathrm{~h})$ in presence and absence of NAC (10 $\mu \mathrm{M})$. c Viability analysis of chaetocin and ABT263 treated cells (100 nM, $1 \mu \mathrm{M}$, respectively for $24 \mathrm{~h}$ ) in the presence or absence of NAC $(10 \mu \mathrm{M})$. $\mathbf{d}$ Western blot showing the effect of NAC $(10 \mu \mathrm{M})$ on activation of main players of apoptosis by chaetocin + TRAlL combinatorial treatment. e Representative fluorescent images from Phospho-H2AX (Ser139) staining showing DNA damage by prolonged exposure to chaetocin (100 nM, $24 \mathrm{~h}$ ), which was blocked by pretreatment with NAC (10uM). Red: H2AX, Blue:DAPI. Scale bar: $10 \mu \mathrm{m}$. f Quantification of Phospho-H2AX (Ser139) staining. Number of \% positive cells was plotted by counting the cells having more than 5 foci. $\mathbf{g} \mathrm{qPCR}$ analysis revealing the modulation of DNA damage related gene expressions; specifically, those involved in mismatch repair pathway (MSH2, MSH6, KU70, and EXO2) and base excision repair (BRCA1 and BRCA2) by chaetocin in ROS-dependent manner. NAC pretreatment $(10 \mu \mathrm{M})$ was performed for $24 \mathrm{~h}$ prior to chaetocin $(100 \mathrm{nM}, 24 \mathrm{~h})$. $\mathbf{h}$ Western blot analysis revealing accumulation of p53 protein in chaetocin $(100 \mathrm{nM}, 24 \mathrm{~h})$ treated cells in ROS-dependent manner. a-tubulin was shown as loading control. $\mathbf{i}$ Viability analysis showing that pretreatment with p53 activator NUTLIN $(10 \mathrm{mM}, 24 \mathrm{~h})$ increased the response of U87MG cells to chaetocin + TRAll treatment (100 nM, $100 \mathrm{ng} / \mathrm{ml}$, respectively). Data were normalized to untreated control. $\left(\left(^{*}\right),\left({ }^{* *}\right)\right.$, and $\left({ }^{* * *}\right)$ denote $P<0.05, P<0.01$ and $P<0.001$, respectively, two-tailed Student's $t$-test). 


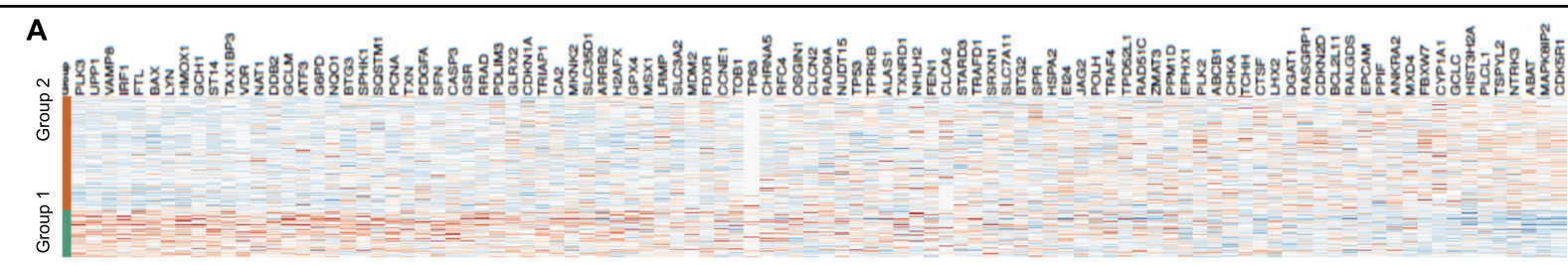

B

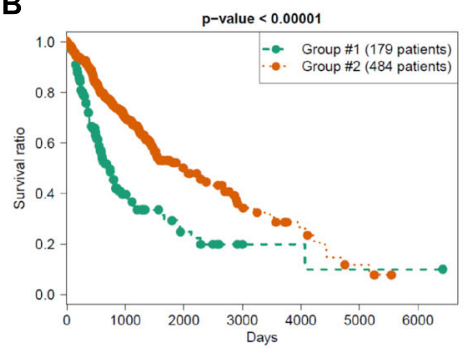

C

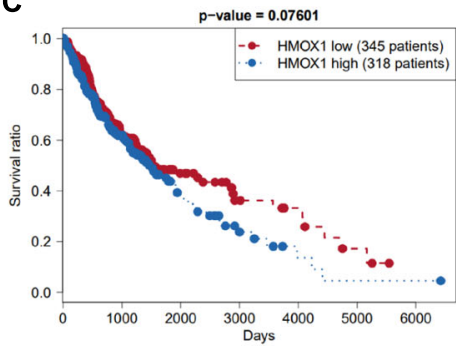

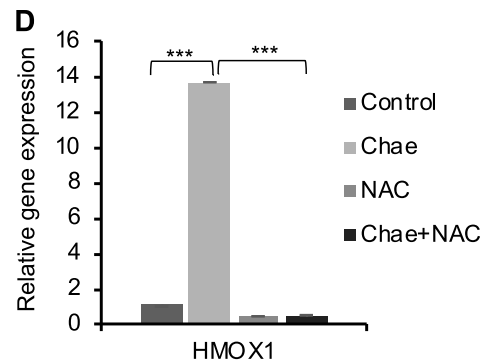

$\mathbf{E}$

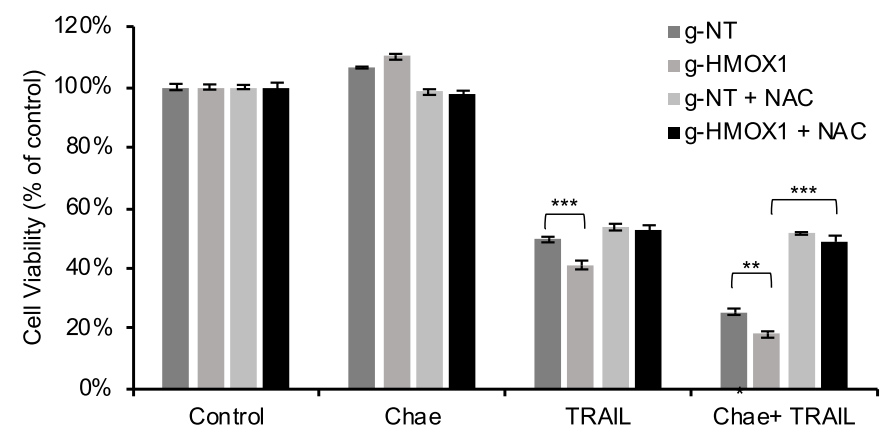

Fig. 7 Depletion of HMOX1, a p53 driven and UV induced gene, further potentiates the response of GBM cells to chaetocin and TRAIL. a Glioma patients ( $n=663$, composed of LGG and GBM patients) from TCGA database were clustered within two distinct groups based on their expression of p53, UV response and ROS related genes from GSEA. b Survival curve for TCGA analysis on 2 distinct groups revealing significant survival difference. c Survival curve of glioma patients (from TCGA database) showing inverse correlation between patient survival and HMOX1 gene expression. $\mathbf{d}$ qPCR data showing upregulation of HMOX1 upon chaetocin treatment in ROS-dependent manner. Data were normalized to untreated control. e Viability analysis showing that HMOX1 knock out sensitized U87MG cells further to TRAIL and chaetocin + TRAIL in ROS-dependent manner. NAC pretreatment $(10 \mu \mathrm{M})$ was performed for $24 \mathrm{~h}$. Data were normalized to untreated control. $\left(\left(^{* *}\right)\right.$ and $\left(^{* *}\right)$ denote $P<0.01$ and $P<0.001$, respectively, two-tailed Student's $t$-test).

(Belinostat, Trichostatin A and SAHA) in accordance with their established role in apoptosis sensitization ${ }^{58}$. We also identified chaetocin as a novel apoptosis regulator in GBM cells. Whilst the relation of chaetocin with death receptor-dependent apoptosis was previously reported $^{59,60}$ and the synergistic cytotoxicity of chaetocin with other epigenetic drugs such as SAHA, JQ- ${ }^{61}$, Trichostain $\mathrm{A}^{62}$, Vorinostat, and $\mathrm{AraC}^{57}$ was previously explored in other cancers, no attempt was made to investigate effect of sub-toxic dose of chaetocin in combination therapies with pro-apoptotic agents. We here demonstrate that low dose chaetocin treatment is sufficient to induce cell death in combination with pro-apoptotic agents such as TRAIL and $\mathrm{BH} 3$ mimetics, suggesting that a brief treatment with chaetocin might be sufficient to prime GBM cells for apoptotic agents. The cooperation between chaetocin and TRAIL involved canonical apoptosis pathways, activation of effector caspases and regulation of DR5, Casp8, Bid, $\mathrm{Bcl} 2$, and BclXL.

In this study, we showed that the antioxidant defense system is initiated in U87MG cells upon chaetocin treatment. Chaetocin led to ROS generation and upregulation of $\mathrm{Nrf}^{63}$ target antioxidant gene expression namely HMOX1, NQO1, GCLM, and TNXRD $1^{64,65}$. We also interrogated the functional role of one of these, HMOX1, in apoptotic response and showed that genetic ablation of HMOX1 further sensitized cells to apoptosis. Also, high HMOX1 expression was negatively correlated with patient survival. Since there are multiple antioxidant genes, effect of a single gene might not broadly represent the correlation between antioxidant defense mechanism and patient survival. Therefore, analyzing the effects of multiple antioxidant defense genes will be critical. We show that chaetocin mediated GBM cell sensitization to 
A

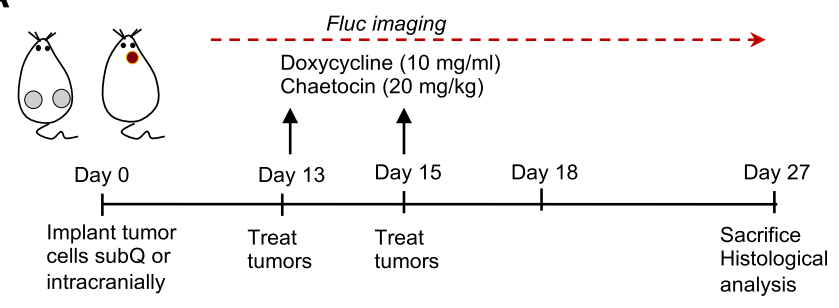

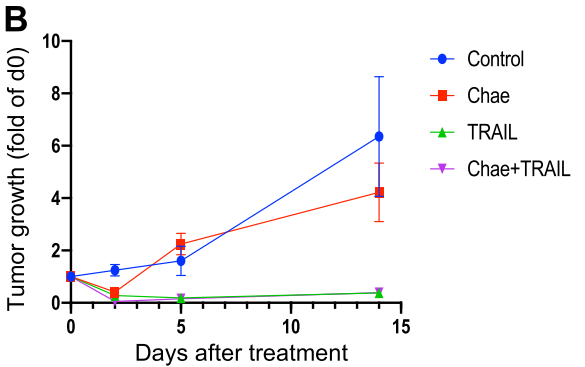
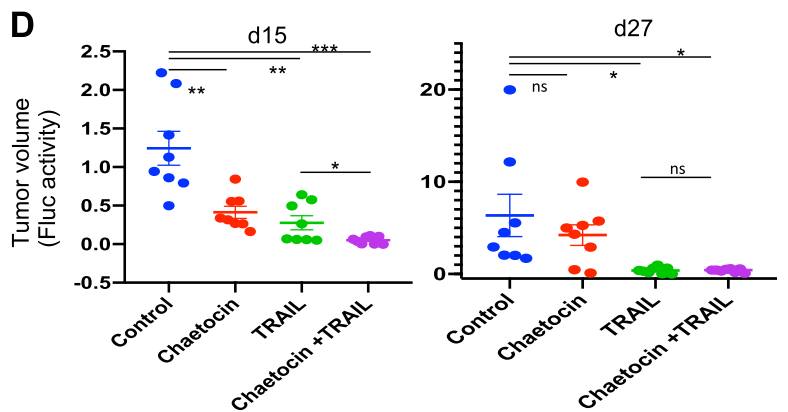

E
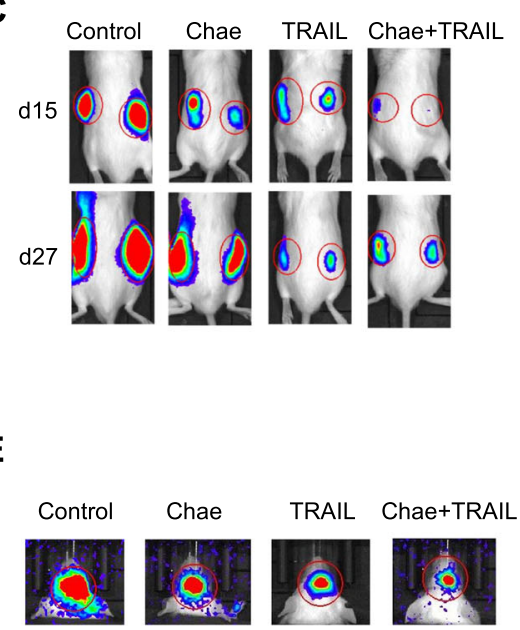

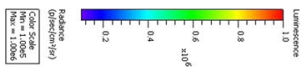

F

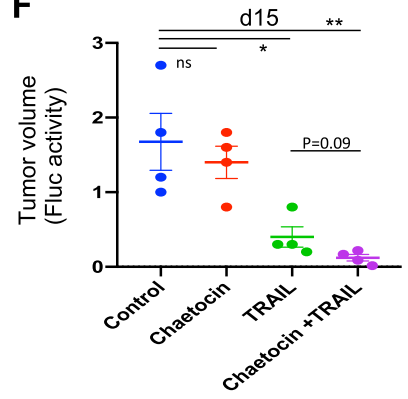

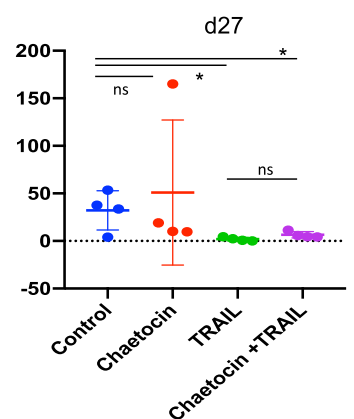

G
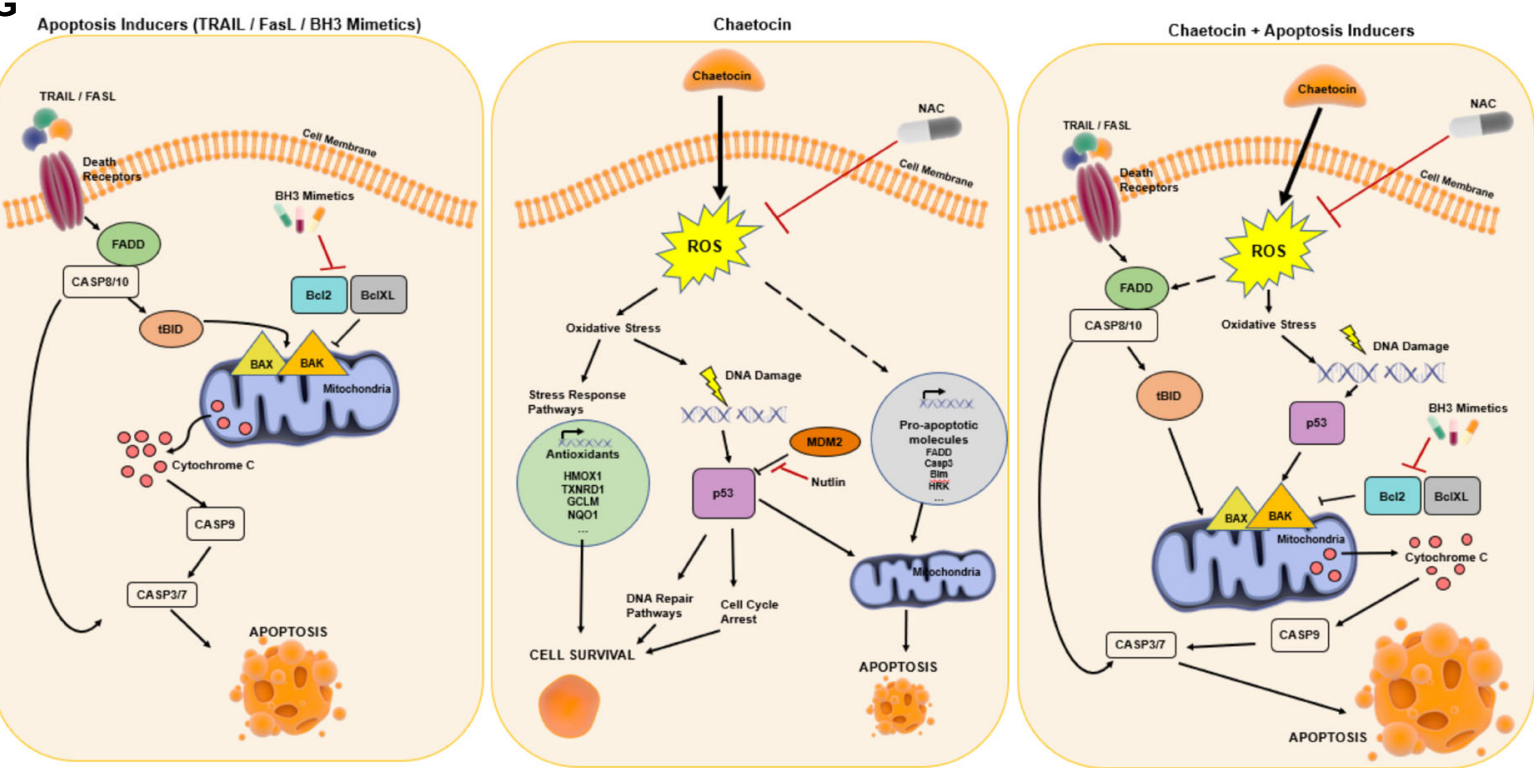

Fig. 8 (See legend on next page.) 
(see figure on previous page)

Fig. 8 Chaetocin and TRAIL cooperate to reduce tumor growth in vivo. a Schematic description of the in vivo experiments. U87MG cells expressing Fluc and mCherry together with an inducible TRAlL vector (Tet-TRAIL) were injected subcutaneously or intracranially to non-obese diabetic/severe combined immunodeficiency (NOD/SCID) mice. Tumor cell injection was confirmed with noninvasive bioluminescence imaging (BLI) on day 0 . After tumors are established, chaetocin + Dox administration was performed at Days 13 and 15. Tumor growth was monitored until Day 27 with BLI. b Graph depicting tumor growth as measured by bioluminescent radiance on 4 time points for 14 days (after treatment). Data were normalized to day 13 (day 0 of drug treatment) signal of each group ( $n=8$ tumors per group). $\mathbf{c}$ Representative images of bilateral tumors from days 15 and 27 displaying normalized bioluminescent efficiencies acquired (blue to red indicates lower to higher radiance as photons/s/cm2/steradian). $\mathbf{d}$ Plots depicting tumor volumes of each subQ tumor on d15 (left) and d27(right). e Representative images of intracranial tumors on d27. f Plots depicting tumor volumes of each intracranial tumor on d15 (left) and d27(right) ( $n=4 /$ group). $\left(\left(^{*}\right)\right.$, $\left({ }^{*}\right)$, and $\left({ }^{* *}\right)$ denote $P<0.05, P<0.01$ and $P<$ 0.001 , respectively, unpaired parametric $t$-test) $\mathbf{g}$ Representative model illustrating chaetocin's mode of action. Extrinsic apoptosis inducers such as TRAIL and FasL bind death receptors and lead to FADD mediated Casp8 activation. Active Casp8 cleaves and activates effector Casp3/7 and leads to apoptosis (extrinsic). Casp8 also truncates BID and cause BAX and BAK oligomerization in mitochondrial outer membrane that leads to Cytochrome C release, consequent activation of Casp9 and effector caspases $3 / 7$ and apoptosis (intrinsic). Intrinsic apoptosis can also be triggered by $\mathrm{BH} 3$ mimetics, which inhibit BCI2 and BCIXL antiapoptotic proteins thus facilitating BAX and BAK activity. Chaetocin elevates cellular ROS levels which cause DNA damage mediated p53 activation. Active p53 leads to cell cycle arrest and trigger DNA repair mechanism rendering mitochondria primed for apoptosis in case damage is unrepairable. ROS also elevates the expression of proapoptotic genes such as FADD and Casp3 and contributes to initiation of apoptosis. Antioxidant defense mechanisms get activated in response to chaetocin treatment to eradicate the detrimental effect of cellular ROS accumulation. When chaetocin is combined with apoptosis inducers, chaetocin mediated primed state of mitochondria, as well as elevated proapoptotic gene expression render cells much more prone to apoptosis induced by any extrinsic (TRAIL/FasL) or intrinsic (BH3 mimetics) stimuli.

TRAIL, FasL, and BH3 mimetics is ROS dependent, supported by several studies showing the interplay between TRAIL-mediated signaling and oxidative stress responses. For example, ROS production was previously shown to upregulate DR5 expression in human carcinoma cell lines ${ }^{66}$. Baicalein ${ }^{67}$ and Vitisin $\mathrm{A}^{68}$ sensitized prostate cancer cells to TRAIL via ROS generation and DR5 upregulation. As another important modulator of oxidative stress response, Glutathione reductase inhibitors potentiated TRAIL toxicity in prostate carcinoma and melanoma ${ }^{69}$.

Chaetocin was illustrated to inhibit the progression of various cancer types including chronic myelogenous leukemia $^{70}$ and non-small cell lung cancer ${ }^{59}$ through oxidative stress induction. Chaetocin was also shown to inhibit invasive ability and trigger cell cycle arrest of the human intrahepatic cholangiocarcinoma in ROS-dependent manner ${ }^{71}$. Our results showing the chaetocin-induced cell cycle arrest are in accordance with these findings. As another literature-supported finding, hallmark EMT pathway was negatively enriched upon chaetocin treatment in our GSEA results.

In glioma, chaetocin was previously shown to induce ROS-mediated apoptosis through the Atm-Yap1 axis and Jnk-dependent metabolic adaptation, where chaetocin reduced lactate levels, ATP production and glucose uptake $^{51}$. In concordance, our GSEA results revealed oxidative phosphorylation and glycolysis as negatively enriched upon chaetocin treatment, implying metabolic rewiring of glioma cells by chaetocin treatment. In glioma, chaetocin mediated activation of JNK resulted in apoptosis via inhibition of $\mathrm{Bcl} 2^{72}$, as well as activation of $\mathrm{p} 53^{73}$, suggesting a similar mechanism as identified in our GBM work. p53 mediated TRAIL sensitization is likely linked to increased expression of p53 target genes such as DR5, $B A X, N O X A$, and PUMA ${ }^{74}$.

Although modulation of SUV39H1 activity can induce ER stress and subsequent apoptosis in lung cancer ${ }^{59}$, we show that chaetocin effects were independent of SUV39H1 regulation. Chaetocin contains the reactive epipolythiodioxopiperazine motif ${ }^{29}$ and apoptosis induction in GBM cells might be attributed to enhanced ROS production through covalent inhibition of TXNRD1 $1^{75,76}$, thereby rendering the ROS defense thioredoxin system inactive.

Taken together, we postulate a model in which ROS production by chaetocin treatment increases the apoptotic priming of GBM cells and renders them more prone to apoptosis initiated by other intrinsic and extrinsic agents. Elevated cellular ROS levels cause DNA damage and p53 activation. Active p53 initiates DNA repair mechanisms and render mitochondria primed for Cytochrome $\mathrm{C}$ release and consequent apoptosis in case damage is unrepairable. To eradicate the detrimental effect of cellular ROS accumulation, antioxidant defense mechanisms get activated in response to chaetocin treatment. When chaetocin is combined with extrinsic and intrinsic apoptosis inducers, ROS mediated primed state of mitochondria, as well as elevated proapoptotic gene expression (FADD, CASP3, CASP8, DR4, PUMA, NOXA, BAD, BIM, and $H R K)$ render cells much more prone to apoptosis (Fig. 8g).

Our identification of chaetocin as an apoptosissensitizer makes it a strong weapon against GBMs, and possibly a wide range of cancers. Importantly, previously revealed ability of chaetocin to cross blood brain barrier ${ }^{51}$, 
as well as our illustration on potency of chaetocin and TRAIL combination in reducing tumor growth in vivo offers a potential therapeutic approach against GBM.

\section{Acknowledgements}

We thank Dr. Nathan Lack (Koç University School of Medicine, Istanbul, TURKEY) for help with the RNA-seq analysis, Dr. Hiroaki Wakimoto (Massachusetts General Hospital, Boston, MA) for providing the primary GBM cells and Dilan Gökyer for assisting experiments. Financial support was obtained from The Scientific and Technological Research Council of Turkey (TUBITAK) BIDEB Program (\#2211e) (EO), Marie Curie FP7 Career Reintegration Grant (EC Grant \# 618673) (TBO), People Programme (Marie Curie Actions) of the European Union's Seventh Framework Programme (FP7/2007-2013) under REA grant agreement no [609305]. (UO), Koç University Center for Translational Medicine (KUTTAM), and Cancer Research UK and the Oxford NIHR Biomedical Research Centre. The SGC (registered charity number 1097737) receives funds from AbbVie, Bayer Pharma AG, Boehringer Ingelheim, Canada Foundation for Innovation, Eshelman Institute for Innovation, Genome Canada, Innovative Medicines Initiative (EU/EFPIA) [ULTRA-DD grant no. 115766], Janssen, Merck KGaA Darmstadt Germany, MSD, Novartis Pharma AG, Ontario Ministry of Economic Development and Innovation, Pfizer, São Paulo Research Foundation-FAPESP, Takeda, and Wellcome [106169/ZZ14/Z].

\section{Author details}

${ }^{1}$ Brain Cancer Research and Therapy Laboratory, Koç University School of Medicine, 34450 Istanbul, Turkey. ${ }^{2}$ Department of Computational Biology, Koç University, 34450 Istanbul, Turkey. ${ }^{3}$ Molecular Biology, Genetics and Bioengineering Program, Faculty of Engineering and Natural Sciences, Sabanci University, Istanbul, Turkey. ${ }^{4}$ Department of Industrial Engineering, College of Engineering, Koç University, İstanbul, Turkey. ${ }^{5}$ Botnar Research Centre, NIHR Biomedical Research Centre Oxford, University of Oxford, Oxford OX3 7LD, UK ${ }^{6}$ Structural Genomics Consortium, University of Oxford, Oxford OX3 7DQ, UK. ${ }^{7}$ FRIAS, Freiburg Institute of Advanced Studies, University of Freiburg, 79104 Freiburg, Germany

\section{Conflict of interest}

The authors declare that they have no conflict of interest.

\section{Publisher's note}

Springer Nature remains neutral with regard to jurisdictional claims in published maps and institutional affiliations.

Supplementary Information accompanies this paper at (https://doi.org/ 10.1038/s41419-019-2107-y).

Received: 4 March 2019 Revised: 12 September 2019 Accepted: 16 October 2019

Published online: 26 November 2019

\section{References}

1. Maleszewska, M. \& Kaminska, B. Is glioblastoma an epigenetic malignancy? Cancers 5, 1120-1139 (2013).

2. Ostrom, Q. T. et al. CBTRUS Statistical Report: primary brain and other central nervous system tumors diagnosed in the United States in 2010-2014. Neuro. Oncol. 19, v1-v88 (2017)

3. Paolillo, M., Boselli, C. \& Schinelli, S. Glioblastoma under siege: an overview of current therapeutic strategies. Brain Sci. 8, 15 (2018).

4. Nørøxe, D. S., Poulsen, H. S. \& Lassen, U. Hallmarks of glioblastoma: a systematic review. ESMO Open 1, e000144 (2016).

5. Preusser, M. et al. Current concepts and management of glioblastoma. Ann. Neurol. 70, 9-21 (2011).

6. Green, D. R. Means To An End: Apoptosis and Other Cell Death Mechanisms. Chicago Journals. (Cold Spring Harbor Laboratory Press, 2010).

7. Pitti, R. M. et al. Induction of apoptosis by Apo-2 ligand, a new member of the tumor necrosis factor cytokine family. J. Biol. Chem. 271, 12687-12690 (1996).
8. Falschlehner, C., Emmerich, C. H., Gerlach, B. \& Walczak, H. TRAlL signalling: decisions between life and death. Int. J. Biochem. Cell Biol. 39, 1462-1475 (2007).

9. Nowsheen, S. \& Yang, E. S. The intersection between DNA damage response and cell death pathways. Exp. Oncol. 34, 243-254 (2012).

10. Merino, D. et al. BH3-mimetic drugs: blazing the trail for new cancer medicines. Cancer Cell 34, 879-891 (2018).

11. Luo, X., Budihardjo, I., Zou, H., Slaughter, C. \& Wang, X. Bid, a BCl2 interacting protein, mediates cytochrome $c$ release from mitochondria in response to activation of cell surface death receptors. Cell 94, 481-490 (1998).

12. Du, C., Fang, M., Li, Y., Li, L. \& Wang, X. Smac, a mitochondrial protein that promotes cytochrome $\mathrm{C}$-dependent caspase activation by eliminating IAP inhibition. Cell 102, 33-42 (2000).

13. Refaat, A., Abd-rabou, A. \& Reda, A. Trail combinations: the new 'trail' for cancer therapy (review). Oncol. Lett. 7, 1327-1332 (2014).

14. MacFarlane, M. et al. Mechanisms of resistance to TRAlL-induced apoptosis in primary B cell chronic lymphocytic leukaemia. Oncogene 21, 6809-6818 (2002).

15. Grotzer, M. et al. Resistance to TRAlL-induced apoptosis in primitive neuroectodermal brain tumor cells correlates with a loss of caspase-8 expression. Oncogene 19, 4604-4610 (2000).

16. Koschny, R. et al. Bortezomib sensitizes primary human astrocytoma cells of $\mathrm{WHO}$ grades I to $\mathrm{N}$ for tumor necrosis factor-related apoptosis-inducing ligand-induced apoptosis. Clin. Cancer Res. 13, 3403-3412 (2007).

17. Knight, M. J., Riffkin, C. D., Muscat, A. M., Ashley, D. M. \& Hawkins, C. J. Analysis of FasL and trail induced apoptosis pathways in glioma cells. Oncogene 20, 5789-5798 (2001).

18. Trivedi, R. \& Mishra, D. P. Trailing TRAIL resistance: novel targets for TRAlL sensitization in cancer cells. Front. Oncol. 5, 69 (2015).

19. Bangert, A. et al. Histone deacetylase inhibitors sensitize glioblastoma cells to TRAlL-induced apoptosis by c-myc-mediated downregulation of CFLIP. Oncogene 31, 4677-4688 (2012).

20. Butler, L. M. et al. The histone deacetylase inhibitor, suberoylanilide hydroxamic acid, overcomes resistance of human breast cancer cells to Apo2L/ TRAlL. Int. J. Cancer 119, 944-954 (2006).

21. Lagneaux, L. et al. Valproic acid induces apoptosis in chronic lymphocytic leukemia cells through activation of the death receptor pathway and potentiates TRAIL response. Exp. Hematol. 35, 1527-1537 (2007).

22. Vanoosten, R. L., Moore, J. M., Ludwig, A. T. \& Griffith, T. S. Depsipeptide (FR901228) enhances the cytotoxic activity of TRAlL by redistributing TRAlL receptor to membrane lipid rafts. Mol. Ther. 11, 542-552 (2005).

23. Zhang, X. D., Gillespie, S. K., Borrow, J. M. \& Hersey, P. The histone deacetylase inhibitor suberic bishydroxamate: a potential sensitizer of melanoma to TNFrelated apoptosis-inducing ligand (TRAIL) induced apoptosis. Biochem. Pharmacol. 66, 1537-1545 (2003).

24. Guo, F. et al. Cotreatment with histone deacetylase inhibitor LAQ824 enhances Apo-2L/tumor necrosis factor-related apoptosis inducing ligandinduced death inducing signaling complex activity and apoptosis of human acute leukemia cells. Cancer Res. 64, 2580-2589 (2004).

25. Fulda, S. \& Debatin, K. M. 5-Aza-2'-deoxycytidine and IFN- $\gamma$ cooperate to sensitize for TRAlL-induced apoptosis by upregulating caspase-8. Oncogene 25, 5125-5133 (2006)

26. Kaminskyyy, V. O, Surovay, O. V., Vaculova, A. \& Zhivotovsky, B. Combined inhibition of DNA methyltransferase and histone deacetylase restores caspase8 expression and sensitizes SCLC cells to TRAIL. Carcinogenesis 32, 1450-1458 (2011).

27. Florean, $\mathrm{C}$. et al. Discovery and characterization of Isofistularin-3, a marine brominated alkaloid, as a new DNA demethylating agent inducing cell cycle arrest and sensitization to TRAlL in cancer cells. Oncotarget 7, 24027-24049 (2016).

28. Kurita, S. et al. DNMT1 and DNMT3b silencing sensitizes human hepatoma cells to TRAlL-mediated apoptosis via up-regulation of TRAIL-R2/DR5 and caspase-8. Cancer Sci. 101, 1431-1439 (2010).

29. Cherblanc, F. L., Chapman, K. L., Brown, R. \& Fuchter, M. J. Chaetocin is a nonspecific inhibitor of histone lysine methyltransferases. Nat. Chem. Biol. 9, 136 (2013).

30. Kurt, I. C. et al. KDM2B, an H3K36-specific demethylase, regulates apoptotic response of GBM cells to TRAIL. Cell Death Dis. 8, e2897 (2017).

31. Cribbs, A. et al. Inhibition of histone H3K27 demethylases selectively modulates inflammatory phenotypes of natural killer cells. J. Biol. Chem. 293, 2422-2437 (2018) 
32. Senbabaoglu, F. et al. Identification of mitoxantrone as a TRAlL-sensitizing agent for glioblastoma multiforme. Cancer Biol. Ther. 17, 546-557 (2016).

33. Love, M. I., Huber, W. \& Anders, S. Moderated estimation of fold change and dispersion for RNA-seq data with DESeq2. Genome Biol. 15, 550 (2014).

34. Mootha, V. K. et al. PGC-1a-responsive genes involved in oxidative phosphorylation are coordinately downregulated in human diabetes. Nat. Genet. 34, 267-273 (2003).

35. Sanjana, N. E., Shalem, O. \& Zhang, F. Improved vectors and genome-wide libraries for CRISPR screening. Nat. Methods 11, 783-784 (2014).

36. Stemmer, M., Thumberger, T., Del Sol Keyer, M., Wittbrodt, J. \& Mateo, J. L. CCTop: an intuitive, flexible and reliable CRISPR/Cas9 target prediction tool. PLOS ONE 10, e0124633 (2015).

37. Olson, a, Sheth, N., Lee, J. S., Hannon, G. \& Sachidanandam, R. RNAi codex: a portal/database for short-hairpin RNA (shRNA) gene-silencing constructs. Nucleic Acids Res. 34, D153-D157 (2006).

38. Onder, T. T. et al. Chromatin-modifying enzymes as modulators of reprogramming. Nature 483, 598-602 (2012).

39. Bagci-Onder, T. et al. Real-time imaging of the dynamics of death receptors and therapeutics that overcome TRAlL resistance in tumors. Oncogene $\mathbf{3 2}$, 2818-2827 (2012)

40. Bagci-Onder, T., Wakimoto, H., Anderegg, M., Cameron, C. \& Shah, K. A dual PI3K/mTOR inhibitor, PI-103, cooperates with stem cell-delivered TRAlL in experimental glioma models. Cancer Res. 71, 154-163 (2011).

41. Lauricella, M., Ciraolo, A., Carlisi, D., Vento, R. \& Tesoriere, G. SAHAVTRAlL combination induces detachment and anoikis of MDA-MB231 and MCF-7 breast cancer cells. Biochimie 94, 287-299 (2012).

42. Huertas, D. et al. Antitumor activity of a small-molecule inhibitor of the histone kinase Haspin. Oncogene 31, 1408-1418 (2012).

43. Zhang, $X$. et al. Identification of 5 -iodotubercidin as a genotoxic drug with anti-cancer potential. PLOS ONE 8, e62527 (2013).

44. Udagawa, S. et al. The production of chaetoglobosins, sterigmatocystin, $\mathrm{O}$ -methylsterigmatocystin, and chaetocin by Chaetomium spp. and related fungi. Can. J. Microbiol. 25, 170-177 (1979).

45. Greiner, D., Bonaldi, T., Eskeland, R., Roemer, E. \& Imhof, A. Identification of a specific inhibitor of the histone methyltransferase SU(VAR)3-9. Nat. Chem. Biol. 1, 143-145 (2005)

46. Tibodeau, J. D., Benson, L. M., Isham, C. R., Owen, W. G. \& Bible, K. C. The anticancer agent chaetocin is a competitive substrate and inhibitor of thioredoxin reductase. Antioxid. Redox Signal. 11, 1097-1106 (2009).

47. Kyrylkova, K., Kyryachenko, S., Leid, M. \& Kioussi, C. Detection of apoptosis by TUNEL assay. Methods Mol. Biol. 887, 41-47 (2012).

48. Tse, C. et al. ABT-263: a potent and orally bioavailable BCl-2 family inhibitor. Cancer Res. 68, 3421-3428 (2008).

49. Lessene, G. et al. Structure-guided design of a selective BCL-XLinhibitor. Nat. Chem. Biol. 9, 390-397 (2013).

50. Chipuk, J. E., Moldoveanu, T., Llambi, F., Parsons, M. J. \& Green, D. R. The BCL-2 family reunion. Mol. Cell 37, 299-310 (2010).

51. Dixit, D., Ghildiyal, R., Anto, N. P. \& Sen, E. Chaetocin-induced ROS-mediated apoptosis involves ATM-YAP1 axis and JNK-dependent inhibition of glucose metabolism. Cell Death Dis. 5, e1212 (2014).

52. Vassilev, L. T. et al. In vivo activation of the p53 pathway by small-molecule antagonists of MDM2. Science 303, 844-848 (2004).

53. Stocker, R., Yamamoto, Y., McDonagh, A. F., Glazer, A. N. \& Ames, B. N. Bilirubin is an antioxidant of possible physiological importance. Science 235, 1043-1046 (1987).

54. Alaoui-Jamali, M. A. et al. A novel experimental heme oxygenase-1-targeted therapy for hormone-refractory prostate cancer. Cancer Res. 69, 8017-8024 (2009).

55. Sass, G. et al. Inhibition of heme oxygenase 1 expression by small interfering RNA decreases orthotopic tumor growth in livers of mice. Int. J. Cancer 123, 1269-1277 (2008)

56. Miyake, M. et al. Inhibition of heme oxygenase-1 enhances the cytotoxic effect of gemcitabine in urothelial cancer cells. Anticancer Res. 30, 2145-2152 (2010).
57. Chaib, H. et al. Anti-leukemia activity of chaetocin via death receptordependent apoptosis and dual modulation of the histone methyl-transferase SUV39H1. Leukemia 26, 662-674 (2012).

58. Zhang, J. \& Zhong, Q. Histone deacetylase inhibitors and cell death. Cell. Mol. Life Sci. 71, 3885-3890 (2014).

59. Liu, X., Guo, S., Liu, X. \& Su, L. Chaetocin induces endoplasmic reticulum stress response and leads to death receptor 5-dependent apoptosis in human non-small cell lung cancer cells. Apoptosis 20, 1499-1507 (2015).

60. Chaib, $\mathrm{H}$. et al. Anti-leukemia activity of chaetocin via death receptordependent apoptosis and dual modulation of the histone methyl-transferase SUV39H1. Leukemia 26, 662-674 (2012).

61. Lai, Y.-S., Chen, J.-Y., Tsai, H.-J., Chen, T.-Y. \& Hung, W.-C. The SUV39H1 inhibitor chaetocin induces differentiation and shows synergistic cytotoxicity with other epigenetic drugs in acute myeloid leukemia cells. Blood Cancer J. 5, e313 (2015).

62. Tran, H. T. T. et al. Improved therapeutic effect against leukemia by a combination of the histone methyltransferase inhibitor chaetocin and the histone deacetylase inhibitor trichostatin A. J. Korean Med. Sci. 28, 237-246 (2013).

63. Sporn, M. B. \& Liby, K. T. NRF2 and cancer: the Good, the bad and the importance of context. Nat. Rev. Cancer 12, 564-571 (2012).

64. Frezza, C. et al. Haem oxygenase is synthetically lethal with the tumour suppressor fumarate hydratase. Nature 477, 225-228 (2011).

65. Mandal, P. K. et al. Loss of thioredoxin reductase 1 renders tumors highly susceptible to pharmacologic glutathione deprivation. Cancer Res. 70, 9505-9514 (2010).

66. Yamaguchi, H. \& Wang, H. G. CHOP is involved in endoplasmic reticulum stress-induced apoptosis by enhancing DR5 expression in human carcinoma cells. J. Biol. Chem. 279, 45495-45502 (2004).

67. Taniguchi, H. et al. Baicalein overcomes tumor necrosis factor-related apoptosis-inducing ligand resistance via two different cell-specific pathways in cancer cells but not in normal cells. Cancer Res. $6 \mathbf{8}$ 8918-8927 (2008).

68. Shin, D. et al. Upregulation of death receptor 5 and production of reactive oxygen species mediate sensitization of $\mathrm{PC}-3$ prostate cancer cells to TRAIL induced apoptosis by vitisin A. Cell. Physiol. Biochem. 36, 1151-1162 (2015).

69. Rozanov, D. et al. TRAIL-based high throughput screening reveals a link between TRAIL-mediated apoptosis and glutathione reductase, a key component of oxidative stress response. PLOS ONE 10, e0129566 (2015).

70. Truitt, L., Hutchinson, C., DeCoteau, J. F. \& Geyer, C. R. Chaetocin antileukemia activity against chronic myelogenous leukemia cells is potentiated by bone marrow stromal factors and overcomes innate imatinib resistance. Oncogenesis 3, e122 (2014)

71. He, J. et al. Chaetocin induces cell cycle arrest and apoptosis by regulating the ROS-mediated ASK-1/JNK signaling pathways. Oncol. Rep. 38, 2489-2497 (2017).

72. Kelkel, M. et al. ROS-independent JNK activation and multisite phosphorylation of $\mathrm{BCl}-2$ link diallyl tetrasulfide-induced mitotic arrest to apoptosis. Carcinogenesis 33, 2162-2171 (2012).

73. Shi, Y. et al. ROS-dependent activation of JNK converts p53 into an efficient inhibitor of oncogenes leading to robust apoptosis. Cell Death Differ. 21, 612-623 (2014)

74. Vousden, K. H. \& Prives, C. Blinded by the light: the growing complexity of p53. Cell 137, 413-431 (2009).

75. Isham, C. R., Tibodeau, J. D., Bossou, A. R., Merchan, J. R. \& Bible, K. C. The anticancer effects of chaetocin are independent of programmed cell death and hypoxia, and are associated with inhibition of endothelial cell proliferation. Br. J. Cancer 106, 314-323 (2012).

76. Isham, C. R. et al. Chaetocin: a promising new antimyeloma agent with in vitro and in vivo activity mediated via imposition of oxidative stress. Blood $\mathbf{1 0 9}$ 2579-2588 (2007). 